\title{
Botrytis pseudocinerea, a New Cryptic Species Causing Gray Mold in French Vineyards in Sympatry with Botrytis cinerea
}

\author{
Anne-Sophie Walker, Angélique Gautier, Johann Confais, Daniel Martinho, Muriel Viaud, \\ Pascal Le Pêcheur, Joelle Dupont, and Elisabeth Fournier
}

First, second, third, fourth, fifth, and sixth authors: INRA UR BIOGER-CPP, Avenue Lucien Brétignières, 78850 Thiverval-Grignon, France; seventh author: UMR 7205, MNHN Département Systématique et Evolution, 57 rue Cuvier, 75231 Paris Cedex 05, France; and eighth author: INRA UMR BGPI, TA A 54/K, Campus International de Baillarguet, 34398 Montpellier Cedex 05, France.

Accepted for publication 28 July 2011.

\begin{abstract}
Walker, A.-S., Gautier, A., Confais, J., Martinho, D., Viaud, M., Le Pêcheur, P., Dupont, J., and Fournier, E. 2011. Botrytis pseudocinerea, a new cryptic species causing gray mold in French vineyards in sympatry with Botrytis cinerea. Phytopathology 101:1433-1445.

Botrytis cinerea is a major crop pathogen infesting $>220$ hosts worldwide. A cryptic species has been identified in some French populations but the new species, B. pseudocinerea, has not been fully delimited and established. The aim of this study was to distinguish between the two species, using phylogenetic, biological, morphological, and ecological criteria. Multiple gene genealogies confirmed that the two species belonged to different, well-supported phylogenetic clades. None of the morphological criteria tested (spore size, germination rate, or mycelial growth) was able to discriminate between these two species.

species were successful. Moreover, population genetics analysis revealed a high level of diversity within each species and a lack of gene flow between them. Finally, a population survey over time showed that $B$. cinerea was the predominant species but that $B$. pseudocinerea was more abundant in spring, on floral debris. This observation could not be explained by temperature adaptation in tests carried out in vitro or by aggressiveness on tomato or bean leaves. This study clearly establishes that $B$. cinerea and $B$. pseudocinerea constitute a complex of two cryptic species living in sympatry on several hosts, including grapevine and blackberry. We propose several biological or molecular tools for unambiguous differentiation between the two species. B. pseudocinerea probably makes a negligible contribution to gray mold epidemics on grapevine. This new species has been deposited in the MycoBank international database.
\end{abstract} Sexual crosses between individuals from the same species and different species were carried out. Only crosses between individuals from the same
Additional keywords: cryptic speciation, fungi, phylogeny.
Species definition has long been a matter of debate in evolutionary biology, leading to various species concepts (35) and, finally, to a consensus that species are segments of evolutionary lineages that evolve independently of each another (5) or subsets of organisms connected to one another through the global genealogical network, existing between two successive speciation events or between a speciation and an extinction (44). Indeed, the issue of species delimitation has long been confused with that of the criteria for species definition $(6,36)$. In operational terms, species criteria are used to recognize and delimit species in experimental studies $(6,49)$. Several such criteria can help to illustrate various species concepts $(21,49)$. The biological species concept (BSC) highlights reproductive isolation (37) and is of particular interest for many fungi, particularly those that can be handled easily and crossed in the laboratory, with the generation of progeny in a reasonable amount of time. The morphological species concept (MSC) is, historically, the criterion most widely used for species delimitation. It is based on morphological similarity. Morphological observations may be challenging in microscopic organisms but the diversity of spores and sexual or asexual structures remains a widely used criterion in the description of fungal entities. The ecological species concept (ESC) focuses on adaptation to particular ecological niches and, thus, is particularly relevant for fungi, which can adapt to a wide range of environments, including extreme ones, due to the variability of

Corresponding author: A.-S. Walker; E-mail address: walker@ versailles.inra.fr

doi:10.1094/PHYTO-04-11-0104

(C) 2011 The American Phytopathological Society their life style (i.e., parasitism, saprophytism, and symbiotism). Finally, the phylogenetic species concept (PSC) distinguishes between species on the basis of nucleotide sequence divergence. Genealogical concordance phylogenetic species recognition (GCPSR) is an extension of the PSC that makes use of the phylogenetic concordance between multiple unlinked genes to indicate a lack of genetic exchange and, thus, the evolutionary independence of lineages. This last criterion is highly discriminating and suitable for use with almost all organisms. Therefore, it has been widely used, particularly for species in which the other criteria have proved not to be relevant. In particular, GCPSR has proved immensely useful for discriminating between cryptic species (i.e., species that are morphologically similar) in fungi $(7,15,27)$.

The mode of speciation is still the subject of active research. Allopatric speciation is thought to occur when groups of organisms are separated by geographic barriers, such as mountains or oceans, preventing gene flow between populations and resulting in reproductive isolation. It has been suggested that this mode of speciation occurs in fungi with no demonstrated substrate specialization (7). Alternatively, isolation may occur within a given geographic area in the absence of an obvious barrier to gene flow, leading to sympatric speciation. Fungi produce large amounts of spores that may easily be dispersed over large distances, reducing the likelihood of allopatric speciation. Ecological speciation (i.e., sympatric speciation promoted by disruptive selection for contrasting ecological niches) is more likely to occur in fungal species reproducing within the habitat in which they grow. For these species, adaptation to a particular niche (i.e., specialization) is a "magic" trait that is sufficient in itself to restrict gene flow in sympatry (20-22). This hypothesis applies 
particularly well to fungi that live as parasite on plants, for which specialization is often strict.

The genus Botrytis (Ascomycota) contains 22 highly specialized species and one hybrid. A multiple-gene genealogy study recently showed that this genus could be subdivided into two clades, one consisting of Botrytis spp. acting as parasites on both monocots and dicots, and the other containing Botrytis spp. acting as parasites on eudicots only (45). Within this second clade, Botrytis cinerea (teleomorph Botryotinia fuckeliana) has the widest host range, being able to infect $>220$ types of eudicot, including grapevine and many fruit and vegetable crops. This species has a highly variable phenotype (i.e., production of sclerotia, density, and color of the mycelium) (34). Genetic diversity, measured either with restriction fragment length polymor- phisms (RFLPs) (19) or microsatellite markers (14), is extremely high in vineyards, and linkage disequilibrium is consistent with regular recombination, even if sexual reproduction is cryptic in nature. Two types of strain have been defined, based on the presence or absence of two transposable elements, boty and flipper $(9,18,31)$ : transposa strains carry both boty and flipper, whereas both of these elements are absent from vacuma strains. Therefore, boty and flipper have frequently been used to characterize Botrytis cinerea populations worldwide $(24,32,38,39,48)$. However, B. cinerea has recently been shown to be a complex of two sibling species living in sympatry and not corresponding to the transposa/vacuma subpopulations (15). B. cinerea sensu stricto is the predominant species, also referred to as group II; it includes both vacuma and transposa strains. The other species,

TABLE 1. Origin of strains and their use in this study

\begin{tabular}{|c|c|c|c|c|c|c|c|c|c|c|c|c|c|c|}
\hline \multirow[b]{2}{*}{ Species $^{\mathrm{a}}$} & \multirow[b]{2}{*}{ Strain } & \multirow[b]{2}{*}{ Origin $^{b}$} & \multirow[b]{2}{*}{ Location } & \multirow[b]{2}{*}{ Year } & \multirow[b]{2}{*}{ Host plant } & \multirow[b]{2}{*}{$\mathrm{Fl}^{\mathrm{c}}$} & \multirow[b]{2}{*}{$\mathrm{Bc}^{\mathrm{d}}$} & \multirow[b]{2}{*}{$\mathrm{Bc} 6^{\mathrm{e}}$} & \multicolumn{6}{|c|}{ Analyses $^{\mathrm{f}}$} \\
\hline & & & & & & & & & Phy & Con & $\mathrm{Ge}$ & $\mathrm{Gr}$ & $\mathrm{T}$ & $\mathrm{Ag}$ \\
\hline \multirow[t]{19}{*}{ Botrytis cinerea } & VD230 & INRA & Courteron, France & 2007 & Vitis vinifera & + & 2 & $\ldots$ & $\mathrm{X}$ & $\mathrm{X}$ & $\mathrm{X}$ & $\mathrm{X}$ & $\ldots$ & $\ldots$ \\
\hline & VD231 & INRA & Courteron, France & 2007 & V. vinifera & + & 2 & 120 & $\mathrm{X}$ & $\mathrm{X}$ & $\mathrm{X}$ & $\mathrm{X}$ & $\ldots$ & $\mathrm{X}$ \\
\hline & 1754 & INRA & Bahlingen, Germany & 1994 & V. vinifera & + & 2 & 120 & $\mathrm{X}$ & $\mathrm{X}$ & $\mathrm{X}$ & $\mathrm{X}$ & $\mathrm{X}$ & $\mathrm{X}$ \\
\hline & 1755 & INRA & Venningen, Germany & 1994 & V. vinifera & + & 2 & 120 & $\mathrm{X}$ & $\mathrm{X}$ & $\mathrm{X}$ & $\mathrm{X}$ & $\ldots$ & $\ldots$ \\
\hline & 1767 & INRA & Kirweiler, Germany & 1995 & V. vinifera & + & 2 & 124 & $\mathrm{X}$ & $\mathrm{X}$ & $\mathrm{X}$ & $\mathrm{X}$ & $\ldots$ & $\ldots$ \\
\hline & 1768 & INRA & Edenkoben, Germany & 1995 & V. vinifera & + & 2 & 120 & $X$ & $\mathrm{X}$ & $\mathrm{X}$ & $\mathrm{X}$ & $\mathrm{X}$ & $\mathrm{X}$ \\
\hline & 1807 & INRA & Cadillac, France & 1996 & V. vinifera & + & 2 & 120 & $\mathrm{X}$ & $\mathrm{X}$ & $\mathrm{X}$ & $\mathrm{X}$ & $\mathrm{X}$ & $\mathrm{X}$ \\
\hline & 1810 & INRA & Athee, France & 1996 & V. vinifera & + & 2 & 120 & $X$ & $\mathrm{X}$ & $\mathrm{X}$ & $\mathrm{X}$ & $\mathrm{X}$ & $\mathrm{X}$ \\
\hline & 1824 & INRA & Tauxières-Mutry, France & 1997 & $V$. vinifera & + & 2 & 120 & $X$ & $\mathrm{X}$ & $\mathrm{X}$ & $\mathrm{X}$ & $\ldots$ & $\ldots$ \\
\hline & 1826 & INRA & Mareuil, France & 1997 & V. vinifera & + & 2 & 120 & $\mathrm{X}$ & $\mathrm{X}$ & $\mathrm{X}$ & $\mathrm{X}$ & $\ldots$ & $\ldots$ \\
\hline & 1905 & INRA & Sydney, Australia & 2001 & $V$. vinifera & + & 2 & $\ldots$ & $X$ & $X$ & $\mathrm{X}$ & $\mathrm{X}$ & $\mathrm{X}$ & $\mathrm{X}$ \\
\hline & 1907 & INRA & Sydney, Australia & 2001 & $V$. vinifera & + & 2 & 120 & $\mathrm{X}$ & $\mathrm{X}$ & $\mathrm{X}$ & $\mathrm{X}$ & $\ldots$ & $\ldots$ \\
\hline & 1909 & INRA & Sydney, Australia & 2001 & V. vinifera & + & 2 & 120 & $X$ & $\mathrm{X}$ & $\mathrm{X}$ & $\mathrm{X}$ & $\ldots$ & $\ldots$ \\
\hline & 1911 & INRA & Sydney, Australia & 2001 & V. vinifera & + & 2 & 124 & $\mathrm{X}$ & $\mathrm{X}$ & $\mathrm{X}$ & $\mathrm{X}$ & $\ldots$ & $\ldots$ \\
\hline & 1916 & INRA & Sydney, Australia & 2001 & V. vinifera & + & 2 & 124 & $\mathrm{X}$ & $\mathrm{X}$ & $\mathrm{X}$ & $\mathrm{X}$ & $\ldots$ & $\ldots$ \\
\hline & SAS405 & U. Bari & Italy & $<1990$ & V. vinifera & $\ldots$ & 2 & $\ldots$ & $\mathrm{X}$ & $\mathrm{X}$ & $\mathrm{X}$ & $\mathrm{X}$ & $\ldots$ & $\ldots$ \\
\hline & SAS56 & U. Bari & Italy & $<1990$ & V. vinifera & + & 2 & 120 & $X$ & $\mathrm{X}$ & $\mathrm{X}$ & $\mathrm{X}$ & $\mathrm{X}$ & $\ldots$ \\
\hline & $\mathrm{T} 4$ & INRA & Eyragues, France & 1991 & Lycopersicon esculentum & $\ldots$ & 2 & 124 & $\mathrm{X}$ & $\mathrm{X}$ & $\mathrm{X}$ & $\mathrm{X}$ & $\ldots$ & $\mathrm{X}$ \\
\hline & B05.10 & U. Münster & Germany & 1994 & Unknown & $\ldots$ & 2 & $\ldots$ & $\ldots$ & $\ldots$ & $\ldots$ & $\ldots$ & $\ldots$ & $\ldots$ \\
\hline \multirow[t]{14}{*}{ B. pseudocinerea } & VD233 & INRA & Courteron, France & 2007 & V. vinifera & - & 1 & 86 & $\mathrm{X}$ & $\mathrm{X}$ & $\mathrm{X}$ & $\mathrm{X}$ & $\ldots$ & $\ldots$ \\
\hline & VD256 & INRA & Courteron, France & 2007 & V. vinifera & - & 1 & 86 & $\mathrm{X}$ & $\mathrm{X}$ & $\mathrm{X}$ & $\mathrm{X}$ & $\mathrm{X}$ & $\mathrm{X}$ \\
\hline & VD296 & INRA & Courteron, France & 2007 & V. vinifera & - & 1 & 86 & $\mathrm{X}$ & $\mathrm{X}$ & $\mathrm{X}$ & $\mathrm{X}$ & $\mathrm{X}$ & $\mathrm{X}$ \\
\hline & VD312 & INRA & Courteron, France & 2007 & V. vinifera & - & 1 & 86 & $\mathrm{X}$ & $\mathrm{X}$ & $\mathrm{X}$ & $\mathrm{X}$ & $\ldots$ & $\ldots$ \\
\hline & VD320 & INRA & Courteron, France & 2007 & V. vinifera & - & 1 & 86 & $\mathrm{X}$ & $\mathrm{X}$ & $\mathrm{X}$ & $\mathrm{X}$ & $\ldots$ & $\ldots$ \\
\hline & VD579 & INRA & Hautvillers, France & 2007 & V. vinifera & - & 1 & 86 & $\mathrm{X}$ & $\mathrm{X}$ & $\mathrm{X}$ & $\mathrm{X}$ & $\mathrm{X}$ & $\mathrm{X}$ \\
\hline & VD606 & INRA & Hautvillers, France & 2007 & V. vinifera & - & 1 & 86 & $X$ & $X$ & $\mathrm{X}$ & $\mathrm{X}$ & $\mathrm{X}$ & $\ldots$ \\
\hline & VD165 & INRA & Vandières, France & 2007 & Rubus fruticosus & - & 1 & 86 & $\mathrm{X}$ & $\mathrm{X}$ & $\mathrm{X}$ & $\mathrm{X}$ & $\ldots$ & $\mathrm{X}$ \\
\hline & VD184 & INRA & Vandières, France & 2007 & R. fruticosus & - & 1 & 86 & $\mathrm{X}$ & $\mathrm{X}$ & $\mathrm{X}$ & $\mathrm{X}$ & $\ldots$ & $\ldots$ \\
\hline & VD195 & INRA & Vandières, France & 2007 & R. fruticosus & - & 1 & 86 & $\mathrm{X}$ & $\mathrm{X}$ & $\mathrm{X}$ & $\mathrm{X}$ & $\ldots$ & $\ldots$ \\
\hline & VD200 & INRA & Vandières, France & 2007 & R. fruticosus & - & 1 & 86 & $\mathrm{X}$ & $\mathrm{X}$ & $\mathrm{X}$ & $\mathrm{X}$ & $\ldots$ & $\ldots$ \\
\hline & VD110 & INRA & Courteron, France & 2007 & V. vinifera & - & 1 & 86 & $\mathrm{X}$ & $\mathrm{X}$ & $\mathrm{X}$ & $\mathrm{X}$ & $\ldots$ & $\ldots$ \\
\hline & VD117 & INRA & Courteron, France & 2007 & V. vinifera & - & 1 & 86 & $X$ & $\mathrm{X}$ & $\mathrm{X}$ & $\mathrm{X}$ & $\mathrm{X}$ & $\ldots$ \\
\hline & VD43 & INRA & Courteron, France & 2007 & $V$. vinifera & - & 1 & 86 & $X$ & $X$ & $\mathrm{X}$ & $\mathrm{X}$ & $\mathrm{X}$ & $\mathrm{X}$ \\
\hline B. aclada & MUCL 8415 & MUCL & Kitzeberg, Germany & 1965 & Allium cepa & $\ldots$ & $\ldots$ & $\cdots$ & $X$ & $\ldots$ & $\ldots$ & $\ldots$ & $\ldots$ & $\ldots$ \\
\hline B. calthae & MUCL 1089 & MUCL & Lovenjoel, Belgium & 1960 & Caltha palustris & $\ldots$ & $\ldots$ & $\ldots$ & $X$ & $\ldots$ & $\ldots$ & $\ldots$ & $\ldots$ & $\ldots$ \\
\hline B. croci & MUCL 436 & MUCL & Breezand, The Netherlands & 1968 & Crocus versicolor & $\ldots$ & $\ldots$ & $\ldots$ & $\mathrm{X}$ & $\ldots$ & $\ldots$ & $\ldots$ & $\ldots$ & $\ldots$ \\
\hline B. fabae & MUCL98 & MUCL & Spain & 1965 & Vicia fabae & $\ldots$ & $\ldots$ & $\ldots$ & $\mathrm{X}$ & $\ldots$ & $\ldots$ & $\ldots$ & $\ldots$ & $\ldots$ \\
\hline B. ficariarum & MUCL 376 & MUCL & Heverlee, Belgium & 1957 & Ficaria verna & $\ldots$ & $\ldots$ & $\ldots$ & $\mathrm{X}$ & $\ldots$ & $\ldots$ & $\ldots$ & $\ldots$ & $\ldots$ \\
\hline B. galanthina & MUCL 435 & MUCL & Texel Is., The Netherlands & 1958 & Galanthus nivalis & $\ldots$ & $\ldots$ & $\ldots$ & $\mathrm{X}$ & $\ldots$ & $\ldots$ & $\ldots$ & $\ldots$ & $\ldots$ \\
\hline B. globosa & MUCL 444 & MUCL & Waterloo, Belgium & 1958 & A. ursinum & $\ldots$ & $\ldots$ & $\ldots$ & $\mathrm{X}$ & $\ldots$ & $\ldots$ & $\ldots$ & $\ldots$ & $\ldots$ \\
\hline B. hyacinthi & MUCL 442 & MUCL & Breezand, The Netherlands & 1958 & Hyacinthus sp. & $\ldots$ & $\cdots$ & $\ldots$ & $X$ & $\cdots$ & $\ldots$ & $\cdots$ & $\ldots$ & $\ldots$ \\
\hline B. narcissicola & MUCL 2120 & MUCL & Hull, Canada & 1961 & Narcissus poeticus & $\ldots$ & $\ldots$ & $\ldots$ & $\mathrm{X}$ & $\ldots$ & $\ldots$ & $\ldots$ & $\ldots$ & $\ldots$ \\
\hline B. pelargonii & CBS 497.50 & CBS & Frederikstad, Norway & 1949 & Pelargonium inquinans & $\cdots$ & $\cdots$ & $\cdots$ & $\mathrm{X}$ & $\cdots$ & $\cdots$ & $\cdots$ & $\ldots$ & $\ldots$ \\
\hline B. porri & MUCL 3234 & MUCL & $\ldots$ & 1926 & A. porrum & $\ldots$ & $\ldots$ & $\ldots$ & $\mathrm{X}$ & $\ldots$ & $\ldots$ & $\ldots$ & $\ldots$ & $\ldots$ \\
\hline B. ranunculi & CBS 178.63 & CBS & Apula, U.S.A. & 1963 & Ranunculus abortivus & $\cdots$ & $\ldots$ & $\cdots$ & $\mathrm{X}$ & $\ldots$ & $\cdots$ & $\cdots$ & $\ldots$ & $\ldots$ \\
\hline B. sphaerosperma & MUCL21482 & MUCL & $\cdots$ & 1963 & A. triquetum & $\cdots$ & $\ldots$ & $\cdots$ & $\mathrm{X}$ & $\ldots$ & $\ldots$ & $\cdots$ & $\ldots$ & $\ldots$ \\
\hline B. squamosa & MUCL1107 & MUCL & California, U.S.A. & 1923 & A. cepa & $\cdots$ & $\cdots$ & $\cdots$ & $\mathrm{X}$ & $\ldots$ & $\ldots$ & $\cdots$ & $\ldots$ & $\ldots$ \\
\hline B. tulipae & ВТ9901 & U. Wageningen & Tollebeet, The Netherlands & 2000 & Tulipa sp. & $\ldots$ & $\ldots$ & $\ldots$ & $\mathrm{X}$ & $\ldots$ & $\ldots$ & $\ldots$ & $\ldots$ & $\ldots$ \\
\hline Sclerotinia sclerotiorum & 1980 & U. Florida & Nebraska, U.S.A. & $\ldots$ & Phaseolus vulgaris & $\ldots$ & $\ldots$ & $\ldots$ & $\mathrm{X}$ & $\ldots$ & $\ldots$ & $\ldots$ & $\ldots$ & $\ldots$ \\
\hline
\end{tabular}

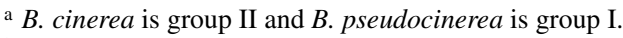

${ }^{\mathrm{b}} \mathrm{U}$. = University of.

c Presence (+) or absence (-) of the transposable element flipper

d Allele found at the $B c$-hch locus (17).

e Allele size found for the microsatellite marker Bc6 (16).

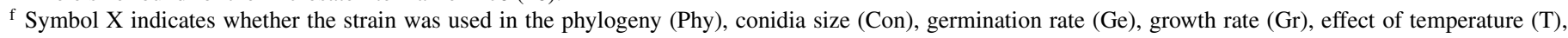
and aggressiveness (Ag) analysis. 
also known as group I, has been found at low frequency in French populations and is suppose to include strains of the vacuma type only. This species also had a different pattern of fungicide susceptibility (phenotype HydR1), displaying natural resistance to fenhexamid and hypersusceptibility to fenpropidin and edifenphos (28). Although these two species are easily separated on the basis of phenotype and several molecular markers $(14,15,17)$, a relevant description and characteristics for identifying Botrytis group I are still lacking, and the phylogenetic position of this species within the genus Botrytis remains unknown. Moreover, the low abundance of this species in French vineyards and its absence from many parts of the world suggest that it may have specific but asyet-undetermined ecological requirements.

The aim of this study was to establish $B$. cinerea group I definitively as a new species, using the species criteria described above, and to complete its description, with the name B. pseudocinerea. The PSC was applied in a multiple-gene genealogy approach, to determine the systematic position of $B$. pseudocinerea in the genus Botrytis. The MSC was applied, with the measurement of several phenotypic characters in both species. The BSC was applied through inter- and intraspecific crosses. We also carried out population genetics analysis to estimate reproductive isolation between populations. Finally, we calculated the relative frequencies, over time, for each species within populations, and carried out aggressiveness and temperature adaptation experiments, to make use of the ESC. A Latin name-based diagnosis system was also generated, with description of the anamorph B. pseudocinerea and the teleomorph Botryotinia pseudofuckeliana.

\section{MATERIALS AND METHODS}

Fungal strains and populations. The fungal strains used for morphological, biological, and phylogenetic characterization were chosen from INRA collections (Table 1). The group II strains had diverse geographic origins, because this group is found worldwide, whereas the group I strains came from France only. B05.10 and $\mathrm{T} 4$ are reference strains, the genomes of which have been fully sequenced and are publicly available (strain T4: http://urgi. versailles.inra.fr/index.php/urgi/Species/Botrytis; strain B0510: http:// www.broadinstitute.org/annotation/genome/botrytis_cinerea/). All strains were purified from a single conidium and cultured on malt-yeast-agar (MYA) medium (malt extract at $20 \mathrm{~g} \mathrm{liter}^{-1}$, yeast extract at $5 \mathrm{~g} \mathrm{liter}^{-1}$, and agar at $12.5 \mathrm{~g} \mathrm{liter}^{-1}$ ), at $19^{\circ} \mathrm{C}$, under continuous illumination, to induce sporulation. Reference strains of various Botrytis spp. were also included (kindly provided by J. van Kan, WUR Wageningen, or bought from the CBS).

The fungal populations analyzed for the assessment of genetic diversity within the two species (Table 2) were collected from vineyards in Champagne, from two host plants (grapevine and blackberry). The fungi were collected from diseased berries in September 2005 and 2006 and from floral debris in June 2006 and 2007. We generated 1,088 single-conidium strains, which were cultured on MYA medium.

All strains were stored as spore suspensions in $20 \%$ glycerol at $-80^{\circ} \mathrm{C}$ and were subcultured on MYA before their use in experiments (Table 1) or genotyping for population genetics analysis.
Nuclear gene sequencing and phylogenetic analysis. DNA was extracted with the DNEasy Plant Mini Kit (Qiagen), adapted for automatic extraction. We assessed the phylogenetic position of the new species within the genus Botrytis by sequencing segments of three nuclear genes for the 31 strains analyzed in this study and for 18 representatives of the genus Botrytis (Table 1). Consistent with the revision of the phylogeny of the genus Botrytis (45), we used the glyceraldehyde 3-phosphate dehydrogenase ( $G 3 P D H$; gene reference in the Botrytis cinerea B0510 genome: BC1G_11968.1) and the heat shock protein 60 (HSP60; gene reference in the $B$. cinerea B0510 genome: BC1G_09341.1) genes. We added one nuclear gene from the Funybase phylogenomic database $(2,33)$ : MS547 (encoding the ATP-dependent RNA helicase DBP7; reference gene in the B. cinerea B0510 genome: BC1G_03202.1). The primers used to amplify MS547 were 5'-AAGGAGGACGTTGGAAGGAT-3' and 5'-AAGTCC AGAATCTCGATGTATTTGT-3'. The three gene fragments were amplified by polymerase chain reaction (PCR) with specific primers, in a total volume of $50 \mu \mathrm{l}$ containing $0.2 \mu \mathrm{g}$ genomic DNA, $5 \mu \mathrm{l}$ of reaction buffer, $1 \mu \mathrm{M} \mathrm{MgCl}_{2}, 2.5 \mu \mathrm{l}$ of a $10 \mu \mathrm{M}$ solution of each primer, and $0.2 \mathrm{U}$ of EUROGENTEC Taq polymerase, with 30 cycles of $30 \mathrm{~s}$ at $94^{\circ} \mathrm{C}, 90 \mathrm{~s}$ at the optimal hybridization temperature for the primers, and $1 \mathrm{~min}$ at $72^{\circ} \mathrm{C}$. The sequences obtained with the two primers were determined directly from PCR products purified on PEG 8000 (polyethylene glycol), with a CEQ8000 capillary sequencing system (Beckman Coulter). Electropherograms were analyzed and sequences were assembled and aligned with the Muscle algorithm and the CodonCode Aligner (CodonCode Corporation).

For each alignment, we identified the DNA substitution model best fitting the data with ModelTest 3.7 (42), which estimates the likelihood of each model and the parameter values under a maximum likelihood framework. The AIC-c criterion was used to rank the 56 different evolution models tested with ModelTest (41). We used the information for the chosen model and its parameters to infer the corresponding maximum likelihood gene trees with PHYML v3.0 (23). Bootstrap analyses (100 replicates) were performed to assess node support. The majority rule criterion was used to obtain the consensus trees from the bootstrap analysis, with the Consense program in the PHYLIP 3.66 package (12). The three datasets were then concatenated, and the same procedure was used to reconstruct the global tree. The topologies of the four individual trees were compared in pairs, and all the individual topologies were compared with the concatenated topology. Trees were compared by eye and by calculating the Icong (8) index of congruence between pairs of trees.

We used two methods to test the molecular clock hypothesis for the three genes. We first carried out Tajima's relative rate test (46), implemented in the MEGA4 package (47). We then used the baseml program of the PAML4 package (51) to test for constant rates of evolution along trees in a maximum likelihood framework.

Sexual crosses. The mating types of the strains included in Figure 1 were checked by PCR amplification with primers amplifying the Botrytis group I or group II MAT locus (A. Gautier, L. Gout, and E. Fournier; personal communication). The MAT1

TABLE 2. Origin and characteristics of Botrytis populations

\begin{tabular}{|c|c|c|c|c|c|c|}
\hline \multirow[b]{2}{*}{ Botrytis spp. } & \multirow[b]{2}{*}{ Host plant } & \multicolumn{4}{|c|}{ Collection date } & \multirow[b]{2}{*}{ Total } \\
\hline & & September 2005 & June 2006 & September 2006 & June 2007 & \\
\hline \multirow[t]{3}{*}{ B. cinerea (group II) } & Grapevine & 209 & 22 & 292 & 106 & 800 \\
\hline & Blackberry & 40 & 215 & 85 & 63 & 210 \\
\hline & Total & 249 & 193 & 377 & 169 & 1,010 \\
\hline \multirow[t]{3}{*}{ B. pseudocinerea (group I) } & Grapevine & 0 & 19 & 11 & 29 & 60 \\
\hline & Blackberry & 0 & 3 & 6 & 9 & 18 \\
\hline & Total & 1 & 22 & 17 & 38 & 78 \\
\hline Total & $\ldots$ & 250 & 237 & 394 & 207 & 1,088 \\
\hline
\end{tabular}


allele yielded a PCR fragment of $\approx 930 \mathrm{bp}$, whereas the MAT2 allele gave a 750-bp amplicon.

Before crosses, each strain was cultured at $17^{\circ} \mathrm{C}$ in the dark on potato dextrose agar (PDA; ready-to-mix Difco at $39 \mathrm{~g} \mathrm{liter}^{-1}$ ) or malt agar (MA; malt at $20 \mathrm{~g} \mathrm{liter}^{-1}$ and agar at $12.5 \mathrm{~g} \mathrm{liter}^{-1}$ ) medium for 2 weeks and was then incubated at $4^{\circ} \mathrm{C}$ for 2 months, to induce the formation of microconidia and sclerotia, respectively. Microconidia from MA petri dishes were scraped into sterile water and sclerotia were collected from PDA cultures by brushing in sterile water to separate them from agar debris and macroconidia. We mixed one to three sclerotia with $3 \mathrm{ml}$ of microconidial spore suspension in six-well microtiter plates, in accordance with the interactions indicated in Figure 1 and including all reciprocal crosses. SAS405 and SAS56 are reference strains from Botrytis group II, and are considered good controls for the production of apothecia (11). Cross preparations were stored at $10^{\circ} \mathrm{C}$ in 16-h photoperiod conditions until apothecia developed. When the apothecia had turned brown, suggesting that they were mature, we dissected a number of apothecia under the microscope, to check for the presence of ascospores.

Morphological and ecological characterization. Suspensions of conidia were obtained by scraping the surface of a 10-day-old sporulated petri dish culture into sterile water. Suspensions were adjusted to a density of 200,000 spores $\mathrm{ml}^{-1}$ with a hemocytometer. Aliquots were observed under the microscope $(\times 200)$ and three pictures were taken for each aliquot. These images were analyzed with ImageJ 1.43 software, to measure the length, width, circumference, and area of at least 100 conidia per strain.

The same spore suspensions were then used to estimate the germination rate of conidia. PDA petri dishes $(50 \mathrm{~mm}$ in diameter) were inoculated with $300 \mu \mathrm{l}$ of spore suspension, and the proportion of spores that germinated was evaluated after $12 \mathrm{~h}$ of incubation in the dark at $19^{\circ} \mathrm{C}$. We also inoculated $100 \mathrm{ml}$ of liquid potato broth medium with the spore suspensions, to a final density of 200,000 spores $\mathrm{ml}^{-1}$. The medium was then incubated in the same conditions, with shaking at $150 \mathrm{rpm}$ on an orbital shaker. The number of spores germinating (germ tube at least as long as the diameter of the spore) was determined under the microscope, with a hemocytometer, for two aliquots from each liquid culture.

Growth rate was estimated by culturing a plug of each strain on solid PDA medium in 90-mm petri dishes, incubated at $19^{\circ} \mathrm{C}$ in the dark. We performed three replicates per strain. For each dish, two diameters of each growing colony were measured daily, until

\section{A G3PDH : 870 sites, model TrNef $+\mathrm{I}+\mathrm{G}$}

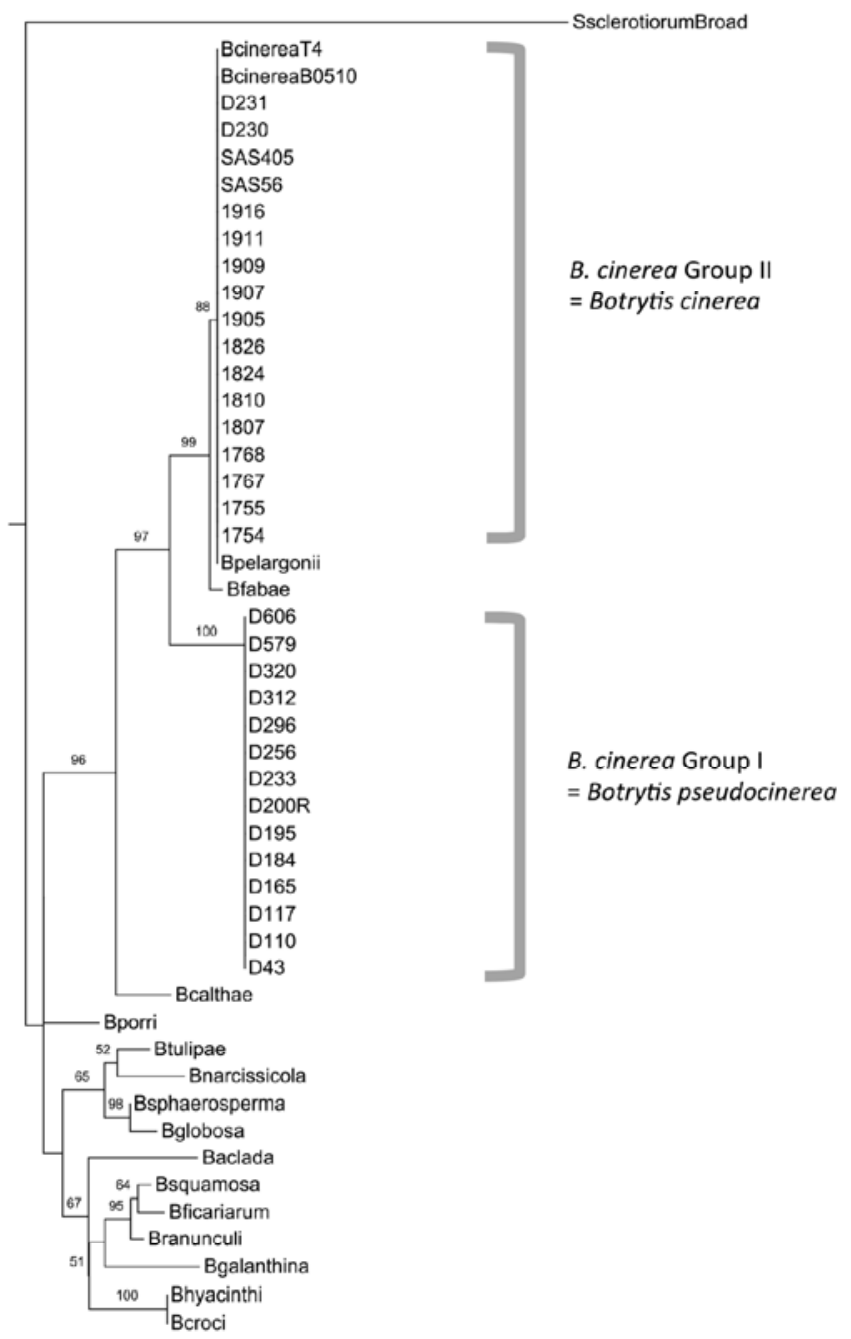

B HSP60: 925 sites, model TrN +G

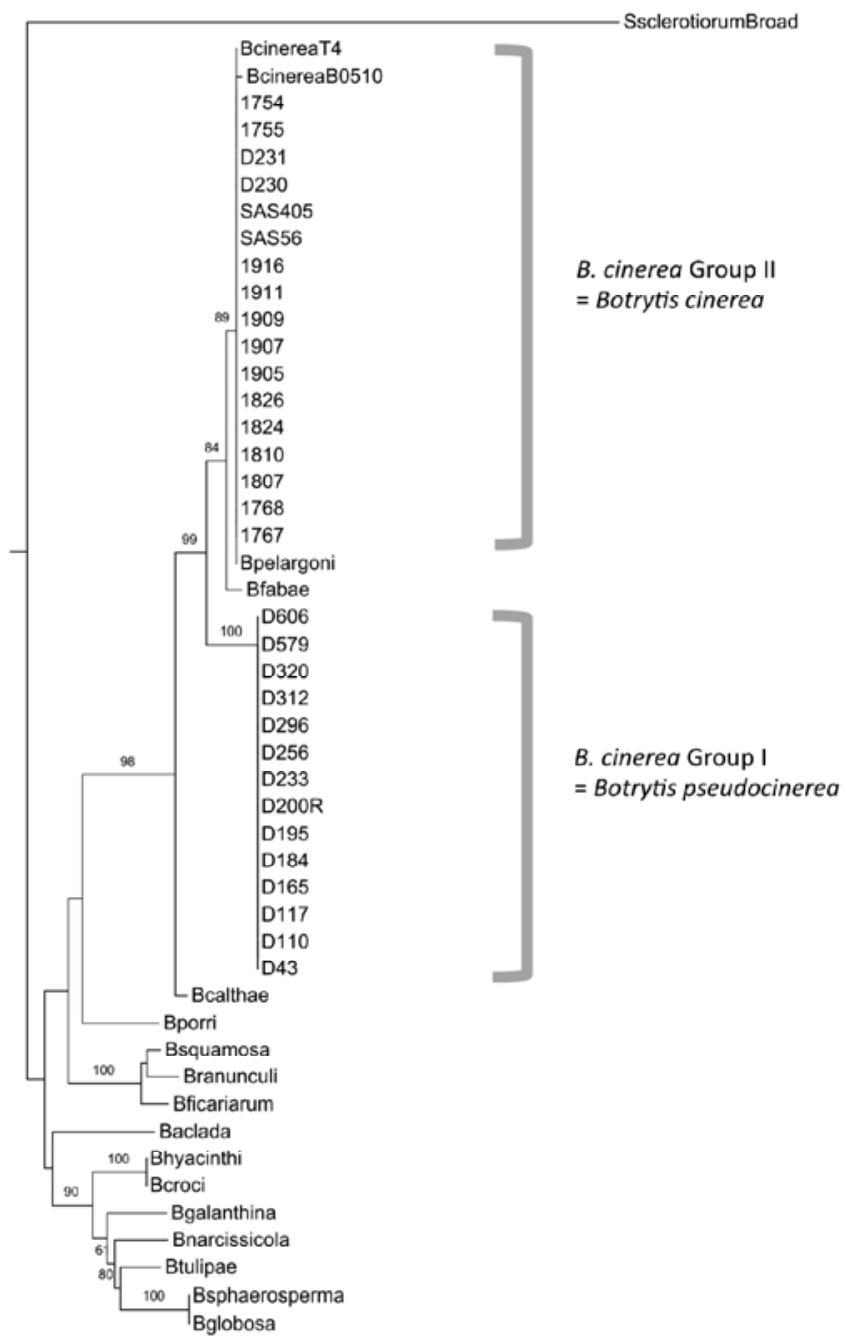

Fig. 1. Phylogenetic position of Botrytis pseudocinerea within the Botrytis genus. Trees were constructed with maximum likelihood methods for the G3PDH, HSP60, and MS547 loci and for the concatenated dataset (the best-fitting substitution model is indicated in parentheses). Bootstrap values $>50 \%$ (after 100 replications) are indicated above branches. The sequences of G3PDH and HSP60 have already been deposited (45). Those of B. cinerea and B. pseudocinerea generated in this study have been deposited in GenBank under accession numbers JF421573-74 and JF421575-76, respectively. Sequences of MS547 established for the various Botrytis species were deposited under accession numbers JF421577-95. 
the culture reached the edge of the dish. The growth rate was then calculated in millimeters per day as the slope of the regression line fitting the curve of mean colony diameter against time.

The diagnosis was established after thorough macroscopic and microscopic examinations of both sexual and asexual stages. The Munsell Book of color (40) was used for color descriptions in the diagnosis of the new species Botryotinia pseudofuckeliana.

We measured fungal aggressiveness on plants by picking leaves from fresh green bean (L2 to L3, 'Caruso') and tomato (L4 to L5, 'Moneymaker') plants and placing them on damp paper in plastic boxes. We placed plugs (5 $\mathrm{mm}$ in diameter) of 4-day nonsporulating mycelium on the surface of the leaves, such that the mycelium was in contact with the unwounded plant tissue (eight to nine replicates per strain). These humid chambers were then incubated at laboratory temperature. The diameter of necrotic lesions was measured daily on four consecutive days. Growth rates were then calculated as described above for mycelial growth.

Optimal growth temperatures were determined by subculturing strains for 7 days in the dark at $7,10,15.5,20$, or $27^{\circ} \mathrm{C}$. We used a minimal medium (glucose at $20 \mathrm{~g} \mathrm{liter}^{-1}, \mathrm{NaNO}_{3}$ at $2 \mathrm{~g} \mathrm{liter}^{-1}$, and agar at $12.5 \mathrm{~g} \mathrm{liter}^{-1}$ ) and MYA medium for each strain (three replicates per strain per medium). Plugs of mycelium (5 $\mathrm{mm}$ in diameter) were deposited in the middle of 90 -mm-diameter petri dishes, such that the mycelium was in contact with the medium.
For each dish, we measured two diameters of the growing colony until the culture reached the edge of the dish (21 days for the most slowly growing cultures). Growth rate was calculated as described above. Sclerotia were counted on all replicates for each strain 3 weeks after inoculation, whatever their size and shape.

Statistical analyses were performed with R. We searched for outliers with boxplots and Cleveland boxplots, and we then used conditional boxplots and QQplots to assess the homoscedasticity and normality of the data. We tested for significant differences between groups for the criteria considered, by carrying out nested analysis of variance ("strain label" being nested within "i") with the LME procedure ("strain label" declared as a random effect). The normality of the residuals was checked by plotting residuals against fitted values, the histogram of residuals, and QQplots of the residuals, and by performing the Shapiro-Wilk tests. For germination rate, an $\arcsin (\ln (x: 100))$ transformation was required to render the data normal.

Genetic differentiation and population phenology. DNA was extracted from fungal populations, as described above (2.2), for phylogenetic studies. Fungal strains (Table 2) were genotyped with eight microsatellites displaying cross-amplification in Botrytis group I and group II (16). We carried out multiplex amplifications, as previously described (30). Population structure was assessed by the clustering method implemented in Structure

\section{MS547: 697 sites, model $\operatorname{TrN}+\mathrm{G}$}

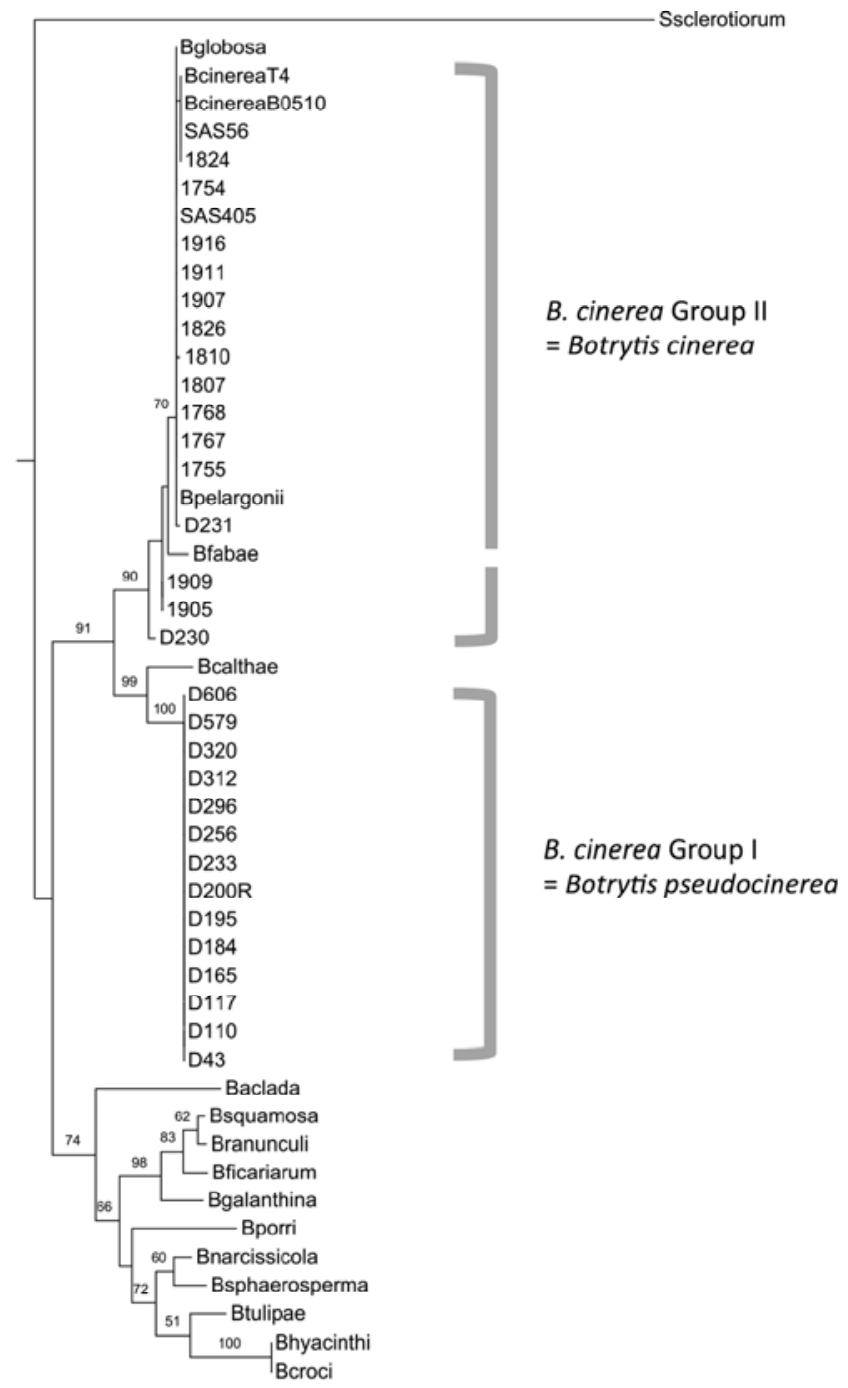

\section{Concatenated: 2492 sites, model $\mathrm{HKY}+\mathrm{I}+\mathrm{G}$}

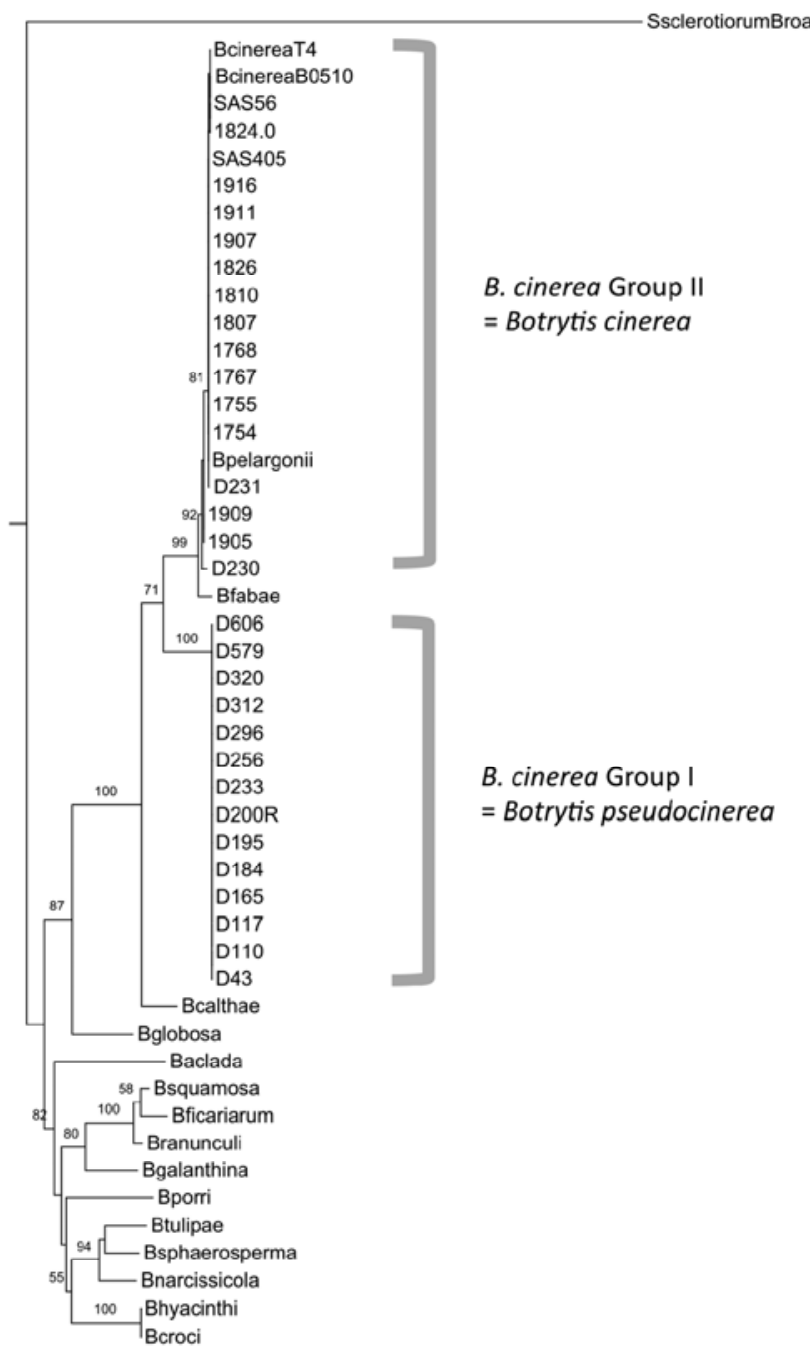

Fig. 1. (Continued from previous page) 
$(10,43)$, with the admixture model and a 10,000-run burn-in period followed by 100,000 Markov Chain Monte Carlo repetitions. The number of unique multilocus genotypes $(\mathrm{G})$, genotypic diversity, and the $r_{d}$ index, an estimate of multilocus linkage disequilibrium and its significance after 1,000 randomizations, were calculated with Gimlet (50) and Multilocus (1), within the K clusters detected after the Structure analysis. We assessed the temporal distribution of the clusters by calculating the frequency of the strains belonging to each cluster for the four collection periods. In addition, the transposable element flipper, which has been used to distinguish subpopulations of Botrytis, was detected in all strains, with primers F300 and F1500 (31). Flipper detection was finally carried out for the Botrytis group I and II strains from Table 1.

Alleles of the microsatellite Bc6 and of the Bc-hch gene (17) were also determined in strains from Table 1 , because private alleles are usually recognized for Botrytis pseudocinerea.

\section{RESULTS}

PSC criterion. We investigated whether Botrytis group I and group II corresponded to isolated gene pools (i.e., phylogenetic species) by assessing the genealogical concordance between three independent nuclear genes (49). We sequenced the G3PDH and HSP60 loci, previously used for revision of the Botrytis genus (45), and we added a third locus, MS547, extracted from the Funybase database (33). Each of the resulting alignments comprised 49 sequences (19 B. cinerea group II; 14 B. cinerea group I; 15 other Botrytis spp., each represented by a single strain; and

TABLE 3. Icong index (8) for all pairs of phylogenetic trees ${ }^{\mathrm{a}}$

\begin{tabular}{lccc}
\hline & HSP60 & MS547 & Concatenated \\
\hline G3PDH & $2.11^{* *}$ & $1.62^{* *}$ & $1.78^{* *}$ \\
HSP60 & $\ldots$ & $1.46^{* *}$ & $1.29 * *$ \\
MS547 & $\ldots$ & $\ldots$ & $2.11^{* *}$ \\
\hline
\end{tabular}

a A significant $P$ value indicates that the compared trees are more congruent than expected by chance alone; ** indicates $P$ values $<0.008$ (the significance threshold after Bonferroni correction).

TABLE 4. Molecular polymorphism at the three loci sequenced in this study

\begin{tabular}{lccc}
\hline Nucleotide differences & G3PDH & HSP60 & MS547 \\
\hline Fixed (total) & 17 & 11 & 19 \\
Fixed in group I and not in group II & 0 & 1 & 11 \\
Fixed in group II and not in group I & 0 & 0 & 0 \\
Shared between group I and II & 0 & 0 & 0 \\
$d_{\text {I }}$ & 0 & 0 & 0 \\
$d_{\text {II }}$ & 0 & $1.1 \times 10^{-4}$ & 0.019 \\
$d_{\text {I-II }}$ & 0.019 & 0.012 & 0.036 \\
$t_{\text {I-II }}$ & 9.8 & 7 & 18 \\
\hline
\end{tabular}

a Symbols: $d_{\mathrm{I}}\left(d_{\mathrm{II}}\right)=$ nucleotide sequence diversity within $B$. cinerea group I (II) $; d_{\mathrm{I}-\mathrm{II}}=$ mean nucleotide sequence diversity between groups (number of nucleotide differences per site); $\mathrm{t}_{\mathrm{I}-\mathrm{II}}=$ divergence time between groups (millions of years), assuming a molecular clock and a mutation rate of $10^{-9}$ substitution/site/year. the Sclerotinia sclerotiorum public sequence from the Broad Institute as an outgroup) and were 870, 925, and $697 \mathrm{bp}$ in length for $G 3 P D H, H S P 60$, and $M S 547$, respectively. In the three genealogies (Fig. 1) estimated by maximum likelihood methods, all group I strains clustered into a fully supported monophyletic lineage (100\% bootstrap support). The sister clade of the group I lineage was well supported in all phylogenies (84 to $99 \%$ bootstrap support). It encompasses all group II strains, together with the $B$. pelargonii representative, separated from the $B$. fabae representative by a strongly supported node, at least in the G3PDH and HSP6O phylogenies (88 and 89\% bootstrap support, respectively). Phylogenetic analysis of the concatenation of the three loci resolved this clade similarly, confirming that Botrytis group I forms a well-supported phylogenetic species that is not the sister species of Botrytis group II (B. fabae branching between them). In all phylogenies, the other Botrytis representatives were grouped in a separate clade, the topology of which was consistent with that reported by Staats et al. (45). The only exception was $B$. globosa in the MS547 phylogeny; its position within the group II lineage may be due to incomplete lineage sorting at this locus, generating unsorted polymorphisms. In addition to comparing topologies by eye, we confirmed the overall congruence between phylogenies by calculating the Icong index (8). The six pairs of topologies tested were more congruent than would be expected by chance alone (Table 3).

Most of the genetic variation at the three loci tested was between groups (Table 4): no mutation was common to two groups, and most were fixed in both species, with the exception of the MS547 locus, for which 11 of the 19 mutations were polymorphic within B. cinerea group II. Tajima's relative rate test for molecular clocks did not reject the hypothesis of a constant rate of evolution along branches in all three topologies (Table 5). This was confirmed by the maximum likelihood test for molecular clocks performed with PAML (data not shown). Because the molecular clock hypothesis was confirmed, we used the mean pairwise nucleotide sequence diversity between groups $\left(d_{\mathrm{I}-\mathrm{II}}\right)$ to estimate the time of divergence between $B$. cinerea groups I and II $\left(t_{\mathrm{I}-\mathrm{II}}=d_{\mathrm{I}-\mathrm{II}} / 2 r\right)$, assuming a mutation rate $(\mathrm{r})$ of $10^{-9}$ substitutions/site/generation (25) (Table 4). Divergence times of 7 to 18 million years were obtained.

MSC criterion. Both Botrytis group I and group II produced tree-like (branched) conidiophores and elliptic conidia (Fig. 2). The larger of the two conidial diameters (the major diameter) did not differ significantly between the two groups $(12.04 \pm 1.55 \mu \mathrm{m}$ for group I and $11.86 \pm 1.45 \mu \mathrm{m}$ for group II) and neither did conidial area $\left(\right.$ mean $=91.29 \pm 21.85 \mu \mathrm{m}^{2}$ for group I and $87.77 \pm$ $18.84 \mu^{2}$ for group II) (Table 6). There was no significant difference between the two groups in terms of the sporulation rate measured on solid PDA (mean $=96.58 \%$ for group I and $94.60 \%$ for group II) or in liquid potato broth $(93.56 \%$ for group I and $92.42 \%$ for group II) (Table 6). The two groups did not differ in growth rate on PDA (mean $=27.10 \mathrm{~mm} /$ day for group I and 25.56 $\mathrm{mm} /$ day for group II) (Table 6). Therefore, we were unable to identify any morphological criterion that reliably distinguished between the two species.

TABLE 5. Tajima's relative rate test of the molecular clock hypothesis ${ }^{\mathrm{a}}$

\begin{tabular}{lccc}
\hline Third sequence & G3PDH & HSP60 & MS547 \\
\hline Botrytis cinerea group II $(1,754)$ & $0.25(0.62)$ & $1.60(0.20)$ & $2.13(0.14)$ \\
B. fabae & $0.06(0.8)$ & $0.33(0.56)$ & $2.13(0.14)$ \\
B. calthae & $0.43(0.5)$ & $3(0.08)$ & $0.06(0.14)$ \\
B. narcissicola & $3.67(0.06)$ & $2.31(0.13)$ & $0.22(0.64)$ \\
B. galanthina & $0.23(0.63)$ & $0.42(0.52)$ & $0.02(0.88)$ \\
B. porri & $1.96(0.16)$ & $2(0.16)$ & $0.08(0.77)$ \\
\hline
\end{tabular}

a Sclerotinia sclerotiorum was considered as the outgroup, and we used Botrytis group I D195 as the reference sequence. The third sequence used for the test is indicated in column 1 . Values shown are $\chi^{2}$ statistics ( $P$ value in parentheses, $1 \mathrm{df}$ ). A nonsignificant $P$ value indicates that the molecular clock hypothesis cannot be rejected. 
BSC criterion. Crosses between and within groups. We carried out 69 intra- and interspecific crosses (8 intragroup II, 50 intragroup I, and 11 intergroup crosses), including 26 control crosses (Fig. 3). As expected, the control cross between SAS56 and SAS405 (11) produced mature apothecia (i.e., containing viable ascospores). The other control crosses of each strain with itself produced no apothecia, as expected. Interspecific crosses of the strains of group I and group II with a strain of the opposite mating type produced viable apothecia in only one case (VD184 $\times$ SAS56), in which a single apothecium devoid of ascospores was produced. These experiments confirmed the existence of a barrier to reproduction between the two species.

The eight crosses in addition to the SAS505 to SAS56 control cross that produced mature apothecia all involved the crossing of strains of opposite mating types from the same group (one intragroup II cross and seven intragroup I crosses). The only exception was the cross between the MAT2 strains VD230 and VD231 (group II), which produced two mature apothecia, possibly due to contamination of this cross or one of the strains being a dualmating type strain. No difference in the production of mature apothecia was observed between species. The size, shape, and color of apothecia from group I, produced here for the first time, were very similar to those of group II, confirming the lack of morphological differences observed at the sexual stage.

Genetic structure between and within B. cinerea groups I and II. We extended the BSC criterion by using population genetics to assess gene flow between the two groups. Single-spore isolates from Botrytis groups I and II used for morphological and phylogenetic characterization (Table 1) were genotyped for several molecular markers. As expected from the results of a previous study (17), all Botrytis group I strains carried allele 1 for the Bchch gene, whereas all group II strains carried allele 2. Furthermore, all the group I strains carried a unique allele (encoded as allele 86 in our genotyping) at the microsatellite locus Bc6. This allele size was not found in any of the tested Botrytis group II strains. Therefore, these two markers can be used to distinguish between the two genetic entities in routine conditions (Table 1). In the reduced dataset used in Table 1, the flipper transposable element was detected in all strains from group II and in none of those from group I (but see below).

We then used the eight microsatellite markers to genotype larger population samples of both species (Table 2). We analyzed the multilocus genotypes of the whole sample (strains from the two cryptic species considered together) or by collection date, using Structure software to determine the optimal number of genetic clusters $(\mathrm{K})$ without the need for prior assumptions. This analysis identified two strongly supported clusters corresponding precisely to groups I and II, referred to hereafter as cluster I and cluster II, respectively. Cluster I contained 78 strains, all from group I, and the mean ancestor probability for this cluster was 0.971. We checked for substructuring within cluster II by performing a second Structure analysis for the individuals of this cluster only. This analysis subdivided cluster II into two clusters: IIa and IIb. Cluster IIa comprised 200 strains, mostly collected from blackberry $(55 \%)$, with a mean ancestor probability of 0.913 , and cluster IIb comprised 810 individuals, mostly collected from grapevine (87\%), with a mean ancestor probability of 0.956 . The flipper transposable element was detected at variable frequency in all clusters and subclusters, including cluster I. The proportion of strains containing flipper within populations differed significantly between seasons $\left(\chi^{2}=38.33, P=0.0005\right.$, df $\left.=8\right)$. The frequency of flipper was higher in clusters IIa and IIb than in cluster I (Fig. 4A), as expected. The number of unique multilocus genotypes (G) was calculated for each cluster and for each collection date. Clonal richness, measured by determining $\mathrm{G} / \mathrm{N}$ ratio, was 0.89 to 1 in clusters I and IIa but lower (0.51 to 0.80$)$ in cluster IIb, indicating a higher proportion of clones in this cluster (Fig. 4B). Clonal richness was systematically higher in June than

in September for cluster IIb, possibly reflecting more intense clonal multiplication between September and August in any given year. The size and level of $\mathrm{G} / \mathrm{N}$ variation of clusters I and IIa were too low for any firm conclusions to be drawn. Genotypic diversity

\section{B. pseudocinerea} (group I)

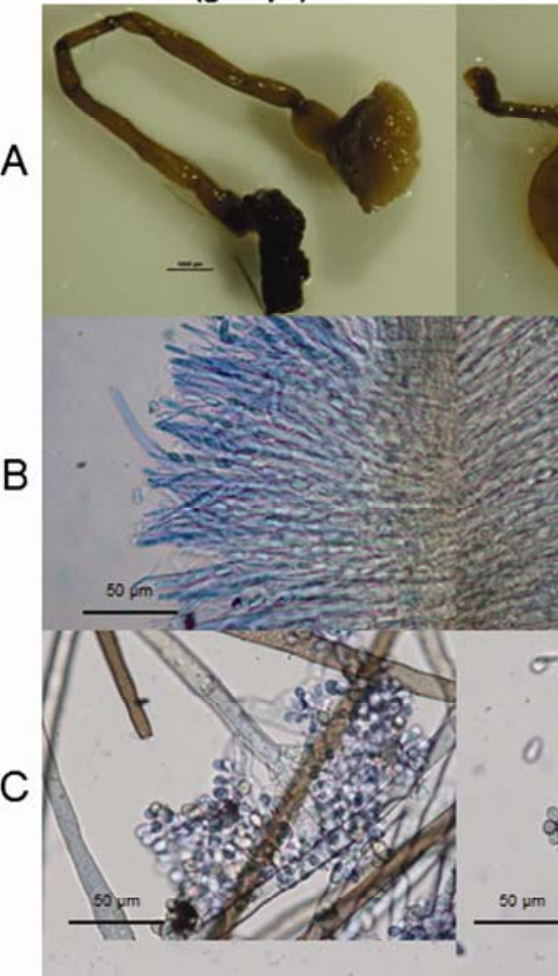

.

$\mathrm{D}$
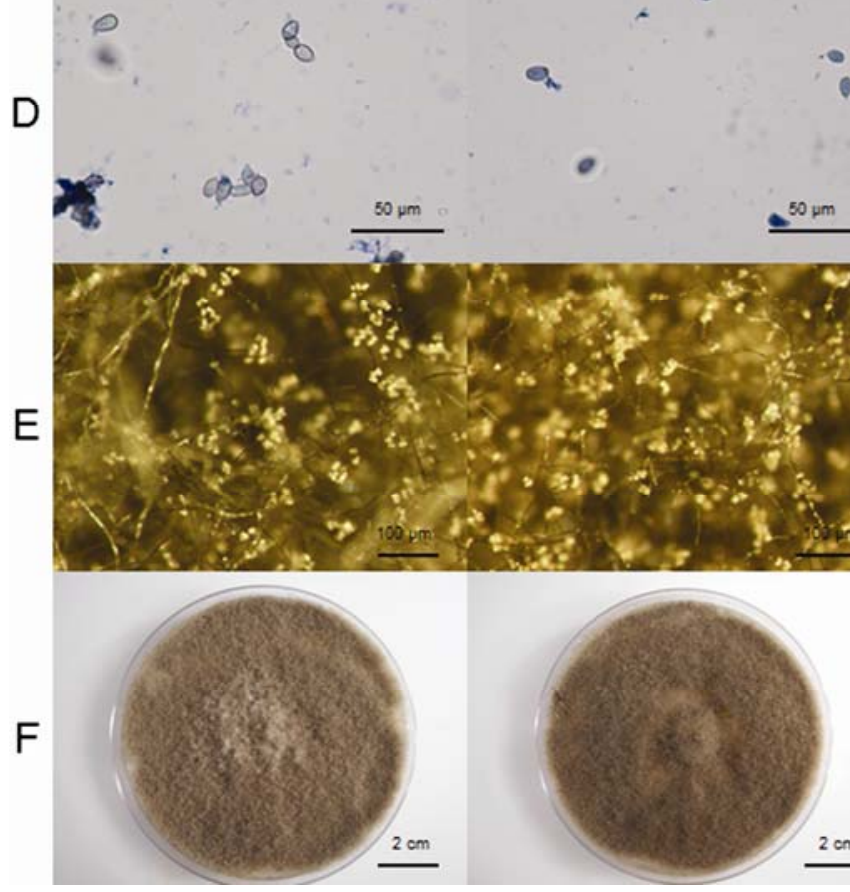

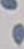

Fig. 2. Morphological characteristics of Botrytis pseudocinerea (left) and Botrytis cinerea (right). A, Apothecia, the sexual structure of Botrytis spp. B, Asci, containing ascospores (sexual spores), observed after the dissection of apothecia. C, Tree-like conidiophores, bearing conidia. D, Conidia (asexual spores). E, Sporulating mycelium (10 days). F, Ten-day sporulating culture on malt-yeast-agar medium. Observation of strains VD256 (B. pseudocinerea) and 1810 (B. cinerea). Typical apothecia obtained after the crosses described in Figure 3. Apothecia obtained after cross VD110 $\times$ VD184 for B. pseudocinerea and VD230 $\times$ VD231 for $B$. cinerea. Cotton blue staining was used for microscopy. 
(Fig. 4C) was $>0.99$ in all clusters at all collection dates. Multilocus linkage disequilibrium, estimated by calculating the $r_{D}$ index (Fig. 4D), was $<0.25$ for all clusters at all collection dates, reflecting very low levels of clonality in all populations $\left(r_{D}=1\right.$ for full clonality). These findings support the hypothesis of regular sexual reproduction in all clusters and, thus, in both species, as previously shown $(14,19)$.

ESC criterion. The proportion of individuals in each cluster at each date was used to compare phenology between the two cryptic species. Groups I and II were found at all collection dates but in very different proportions, indicating phenological differences between the two species, although these differences were not significant over time $\left(\chi^{2}=3.24, P=0.357\right.$, df $=3$ ) (Fig. 4A). Group II strains were systematically the most frequent but group I strains were more abundant in June $(9.3$ and $18.4 \%$ of the whole population in 2006 and 2007, respectively) than in September (0.4 and $4.3 \%$ of the whole population in 2005 and 2006, respectively). It is cooler early in the season and the June strains were collected from dead floral debris, whereas the September strains were collected from living berries. Therefore, we checked for ecological adaptation of the two species by assessing their aggressiveness on plants and their tolerance to extreme temperatures.

In planta aggressiveness was measured on tomato and bean plants from which none of the strains were collected, to limit bias due to host plant adaptation. Both species grew more slowly on tomato leaves $(6.08 \pm 0.38 \mathrm{~mm} /$ day for group I strains and $5.57 \pm$ $0.39 \mathrm{~mm} /$ day for group II strains) than on green bean leaves $(9.93 \pm 0.41 \mathrm{~mm} /$ day for group I strains and $12.38 \pm 0.34 \mathrm{~mm} /$ day for group II strains) but the difference in growth between groups I and II was not significant, regardless of the plant considered $(P=$ 0.26 on tomato and 0.06 on green bean leaves, respectively) (Fig. 5). Similarly, we found no significant difference in optimal growth temperature or tolerance to extreme temperatures between the two species (Table 6). Temperature had a significant effect in both species when colonies were grown on rich medium, with an opti- mum growth temperature of $20^{\circ} \mathrm{C}$ (mean growth at this temperature $=21.80 \mathrm{~mm} /$ day for group I and $21.27 \mathrm{~mm} /$ day for group II) but no such effect was observed on minimal medium. Neither the group effect nor the interaction between temperature and group was significant, indicating that growth rates at the temperatures tested and optimal temperatures were similar for both groups. On minimal medium, the number of sclerotia produced differed significantly between groups I and II $(P=0.04$ for the group effect) at all tested temperatures $\left(P=10^{-4}\right.$ for the temperature effect) but the direction of the difference was changed between temperatures $\left(P=10^{-4}\right.$ for the group-temperature interaction). These significant effects were not found on rich medium.

\section{DISCUSSION}

Identification of a new Botrytis sp. On the basis of several classical descriptors (e.g., phenotypic, ecological, and genetic), $B$. cinerea has long been known to be a highly variable species $(18,34)$. Giraud et al. (19) was the first to suspect that there were two separate genetic entities, on the basis of RFLP and transposable element data, but was unable to delimit these two entities adequately. $B$. cinerea has recently been effectively divided into two hermetic gene pools, groups I and II (15). However, there was no complete description of the new species corresponding to $B$. cinerea group I. In this study, we used several species criteria to develop an unequivocal description of the former $B$. cinerea group I as a new species. We compared the genealogies of three new nuclear loci, applying the PSC, and confirmed that $B$. cinerea group I corresponded to an isolated gene pool (i.e., a phylogenetic species). This was also confirmed by population genetic analysis based upon microsatellite markers. Several combinations of sexual crosses confirmed the status of B. cinerea group I as a biological species, in accordance with the BSC. We were unable to distinguish between the two species according to the MSC, because they did not differ significantly for any of the morphological characters measured (major diameter and area of conidia, growth

TABLE 6. Morphological and ecological characteristics of Botrytis pseudocinerea and to B. cinere $^{\text {a }}$

\begin{tabular}{|c|c|c|c|}
\hline Measured criterion ${ }^{\mathrm{b}}$ & B. cinerea (group II) & B. pseudocinerea (group I) & $P$ value ${ }^{\mathrm{c}}$ \\
\hline Conidial major diameter $(\mu \mathrm{m})$ & $11.86 \pm 1.45$ & $12.04 \pm 1.55$ & 0.14 \\
\hline Conidial area $\left(\mu \mathrm{m}^{2}\right)$ & $87.77 \pm 18.84$ & $91.29 \pm 21.85$ & 0.08 \\
\hline Germination rate $(\%)$ on solid PDA medium & $94.60 \pm 5.65$ & $96.58 \pm 3.72$ & 0.83 \\
\hline Germination rate $(\%)$ on liquid PDB medium & $92.42 \pm 6.77$ & $93.56 \pm 4.57$ & 0.52 \\
\hline Growth rate (mm/day) on PDA medium & $25.56 \pm 4.61$ & $27.10 \pm 2.96$ & 0.29 \\
\hline \multicolumn{4}{|l|}{ Growth rate (mm/day) on minimum medium at } \\
\hline $7^{\circ} \mathrm{C}$ & $7.85 \pm 1.35$ & $5.62 \pm 1.56$ & $\ldots$ \\
\hline $10^{\circ} \mathrm{C}$ & $10.86 \pm 1.87$ & $8.83 \pm 1.98$ & $\ldots$ \\
\hline $15.5^{\circ} \mathrm{C}$ & $15.63 \pm 2.80$ & $12.28 \pm 2.82$ & G: 0.08 \\
\hline $20^{\circ} \mathrm{C}$ & $16.67 \pm 1.40$ & $15.63 \pm 1.91$ & T: 0.98 \\
\hline $27^{\circ} \mathrm{C}$ & $4.14 \pm 0.87$ & $3.92 \pm 0.57$ & $\mathrm{G} \times \mathrm{T}: 0.31$ \\
\hline \multicolumn{4}{|l|}{ Growth rate $(\mathrm{cm} /$ day) on MYA medium at } \\
\hline $7^{\circ} \mathrm{C}$ & $6.05 \pm 1.20$ & $7.16 \pm 0.83$ & $\ldots$ \\
\hline $10^{\circ} \mathrm{C}$ & $10.19 \pm 1.52$ & $11.39 \pm 1.57$ & $\ldots$ \\
\hline $15.5^{\circ} \mathrm{C}$ & $16.66 \pm 0.91$ & $17.25 \pm 0.17$ & G: 0.59 \\
\hline $20^{\circ} \mathrm{C}$ & $21.27 \pm 0.40$ & $21.80 \pm 0.29$ & $\mathrm{~T}: 0.004$ \\
\hline $27^{\circ} \mathrm{C}$ & $4.52 \pm 2.17$ & $10.20 \pm 2.48$ & $\mathrm{G} \times \mathrm{T}: 0.17$ \\
\hline \multicolumn{4}{|l|}{ Number of sclerotia on minimum medium at } \\
\hline $7^{\circ} \mathrm{C}$ & $73.33 \pm 72.43$ & $34.05 \pm 12.02$ & $\ldots$ \\
\hline $10^{\circ} \mathrm{C}$ & $79.22 \pm 41.72$ & $72.22 \pm 17.93$ & $\ldots$ \\
\hline $15.5^{\circ} \mathrm{C}$ & $78.83 \pm 32.11$ & $103.50 \pm 15.64$ & G: 0.004 \\
\hline $20^{\circ} \mathrm{C}$ & $76.05 \pm 31.62$ & $117.39 \pm 20.26$ & $\mathrm{~T}: 10^{-4}$ \\
\hline $27^{\circ} \mathrm{C}$ & $31.22 \pm 37.15$ & $105.72 \pm 138.23$ & $\mathrm{G} \times \mathrm{T}: 10^{-4}$ \\
\hline \multicolumn{4}{|l|}{ Number of sclerotia on MYA medium at } \\
\hline $7^{\circ} \mathrm{C}$ & $106.33 \pm 105.08$ & $20.28 \pm 16.61$ & $\ldots$ \\
\hline $10^{\circ} \mathrm{C}$ & $55.78 \pm 45.78$ & $47.72 \pm 14.63$ & $\ldots$ \\
\hline $15.5^{\circ} \mathrm{C}$ & $77.33 \pm 43.38$ & $85.06 \pm 18.34$ & G: 0.86 \\
\hline $20^{\circ} \mathrm{C}$ & $45.22 \pm 20.53$ & $84.56 \pm 15.15$ & $\mathrm{~T}: 0.24$ \\
\hline $27^{\circ} \mathrm{C}$ & $196.17 \pm 173.13$ & $43.22 \pm 38.41$ & $\mathrm{G} \times \mathrm{T}: 0.07$ \\
\hline
\end{tabular}

${ }^{a}$ Measurements are mean value for each species, followed by standard deviation.

b $\mathrm{PDA}=$ potato dextrose agar, $\mathrm{PDB}=$ potato dextrose broth, and MYA = malt-yeast-agar.

${ }^{\text {b }} P$ value of the group $(\mathrm{G})$ effect, unless another factor or interaction is specified; $\mathrm{T}=$ temperature effect. 
rates, and conidial germination rates on different media). Nevertheless, conidial area was higher in group I than in group II and this difference was close to the threshold for statistical significance $(P=0.08)$, and this is consistent with previous observations (15). Finally, according to the ESC, the only element confirming that $B$. cinerea group I was a new species was the difference in phenology, this species being found predominantly in spring, at least on grapevine and blackberry. However, this finding was not supported by differences in optimal temperature in tests in vitro. We suggest that this species should be named Botrytis pseudocinerea (anamorph)/Botryotinia pseudofuckeliana (teleomorph). The name Botrytis cinerea (anamorph)/Botryotinia fuckeliana should, hereafter, refer to Botrytis cinerea group II only. We provide below a diagnosis of this new species.

Botryotinia pseudofuckeliana A.-S. Walker, A. Gautier, J. Confais, D. Martinho, M. Viaud, P. Lepêcheur, J. Dupont, E. Fournier, sp. nov. MycoBank no.: MB 561818

Fungus heterothallicus. Apothecia cupulata et longo stipite praedita, infundibuliformia, extus intusque brunnea, usque ad $3.5 \mathrm{~mm}$ diam lata. Stipes concolor, flexuosus, usque ad $15 \mathrm{~mm}$ longus, oriens ex nigris sclerotiis. Asci cylindracei, octaspori, $150 \mu \mathrm{m}$ longi, mixti paraphysibus filiformibus, hyalinis. Ascosporae unicellulares, hyalinae, ovoideae, 12 to $16 \times 4.5$ to $5.5 \mu \mathrm{m}$.

Status anamorphus: Botrytis pseudocinerea.

Botrytis pseudocinerea A.-S. Walker, A. Gautier, J. Confais, D. Martinho, M. Viaud, P. Lepêcheur, J. Dupont, E. Fournier, sp. nov.

Coloniae in PDA ad $19^{\circ} \mathrm{C} 27 \mathrm{~mm}$ diam d $\mathrm{d}^{-1}$, effusae, griseae. Sclerotia grisea vel nigra, solitaria vel gregaria. Conidiophori simplices, erecti, septati, brunnei, cellulis conidiiferis leviter inflatis ad apicem praediti. Conidia racemosa, unicellularia, hyalina vel brunnea, ellipsoidea vel ovoidea, 8 to $13 \times 5$ to $6.5 \mu \mathrm{m}$. Spermatia unicellularia, hyalina, globosa, 2.5 to $3 \mu \mathrm{m}$ diam, orientia ex phialidibus aggregatis in spermodochiis.

Heterothallic. Apothecia cupulate and stalked, dark reddish brown $(5 \mathrm{YR} / 3 / 2$ to $5 \mathrm{YR} / 3 / 3$ after (40). Cup infundibuliform up to $3.5 \mathrm{~mm}$ diam. Stipes flexuous, same color, up to $15 \mathrm{~mm}$ long, arising from black (2.5Y/2/0) sclerotia. Asci cylindrical, 8-spored, $150 \mu \mathrm{m}$ long, interspersed with filiform, hyaline, paraphyses. Ascospores ovoid, hyaline, 12 to $16 \times 4.5$ to $5.5 \mu \mathrm{m}$. Anamorph: Botrytis pseudocinerea.

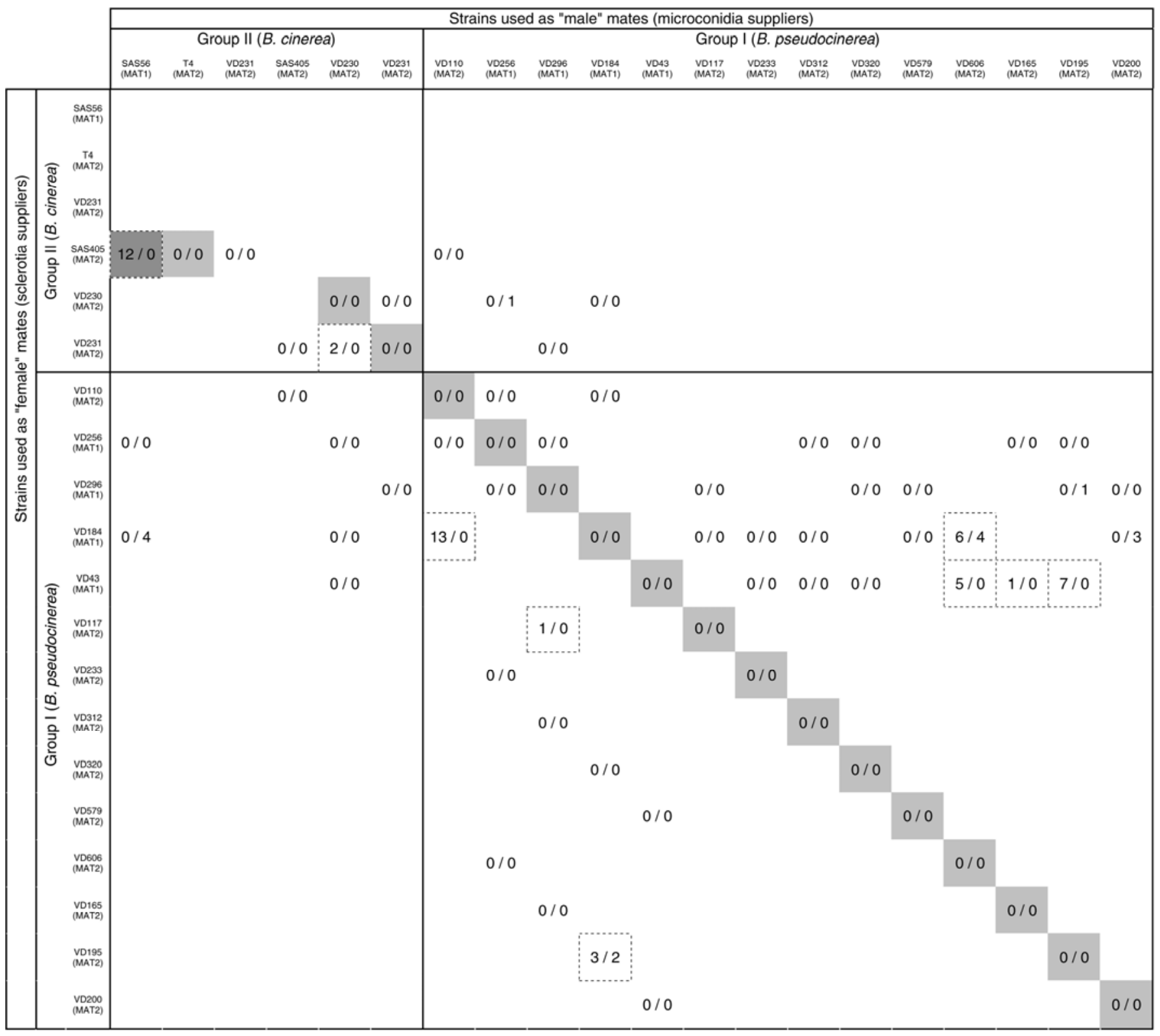

Fig. 3. Sexual crosses between Botrytis strains. Pale gray boxes indicate control crosses. The dark gray box corresponds to the SAS405 $\times$ SAS56 cross, considered as the reference cross in literature. Left and right numbers indicate the number of mature and aborted apothecia produced, respectively. Boxed cells indicate crosses that produced at least one viable apothecia. 
On PDA at $19^{\circ} \mathrm{C}$ in the dark, radial mycelial growth rate $27 \mathrm{~mm} \mathrm{~d}{ }^{-1}$, colony surface gray $(10 \mathrm{YR} / 6 / 1)$. Sclerotia gray $(2.5 \mathrm{Y} / 3 / 0)$ to black $(2.5 \mathrm{Y} / 2 / 0)$, solitary or aggregated. Conidiophores simple, erect, septate, and brown, bearing alternate conidiogenous cells slightly inflated at the apex. Conidia in botryose clusters, one-celled, hyaline to pale brown, elliptical to ovoid, 8 to $13 \times 5$ to $6.5 \mu \mathrm{m}$. Spermatia one-celled, hyaline, globose, 2.5 to $3 \mu \mathrm{m}$ in diam produced from phialides aggregated into clusters forming spermodochia.

Isolation: ex petal cap of Vitis vinifera from the Champagne vineyard, Courteron, France, 2007, collector A.-S. Walker.

Holotypus: The type specimen PC0655988, deposited in Paris herbarium (PC) is a dried culture from a pair of the isolates VD110 $\times$ VD184. Ex type: live cultures of isolates VD110 and VD184 deposited at the Fungal Culture Collection of the national Museum of natural history, Paris, with accession number LCP 05896 and LCP 05897, respectively).

Divergence between $B$. cinerea and $B$. pseudocinerea. Our study revealed that $B$. cinerea and $B$. pseudocinerea are not sister species, the species most closely related to $B$. cinerea being $B$. fabae. Considering the three genes used for our phylogeny to have evolved clockwise, and assuming a mutation rate of $10^{-9}$ substitution/site/year, a reasonable value for filamentous fungi (25), we estimated a divergence time between $B$. cinerea and $B$. pseudocinerea of 7 to 18 million years. These values are similar to the 7 to 15.5 million years reported in a previous study with four different nuclear genes (15) and confirm that the speciation between $B$. pseudocinerea and the common ancestor of $B$. cinerea and $B$. fabae is ancient. Moreover, because most crosses between groups I and II produced no viable apothecia, the reproductive barrier may be due to prezygotic isolation, as is often reported for ancient or sympatric divergences (26).

Further investigations are required to disentangle the speciation mechanisms and dynamics responsible for the divergence between B. pseudocinerea, B. cinerea, and B. fabae. B. cinerea and $B$. pseudocinerea have similar large host ranges and are found in sympatry but clearly differ in their phenology, demonstrating differences in ecological niche. If these species diverged in sympatry through ecological speciation (20), the adaptive traits targeted by disruptive selection might be related to climate, plant phenology, or trophic resources. We found no difference in cold tolerance or aggressiveness on living plants but many other param-

A

population structure

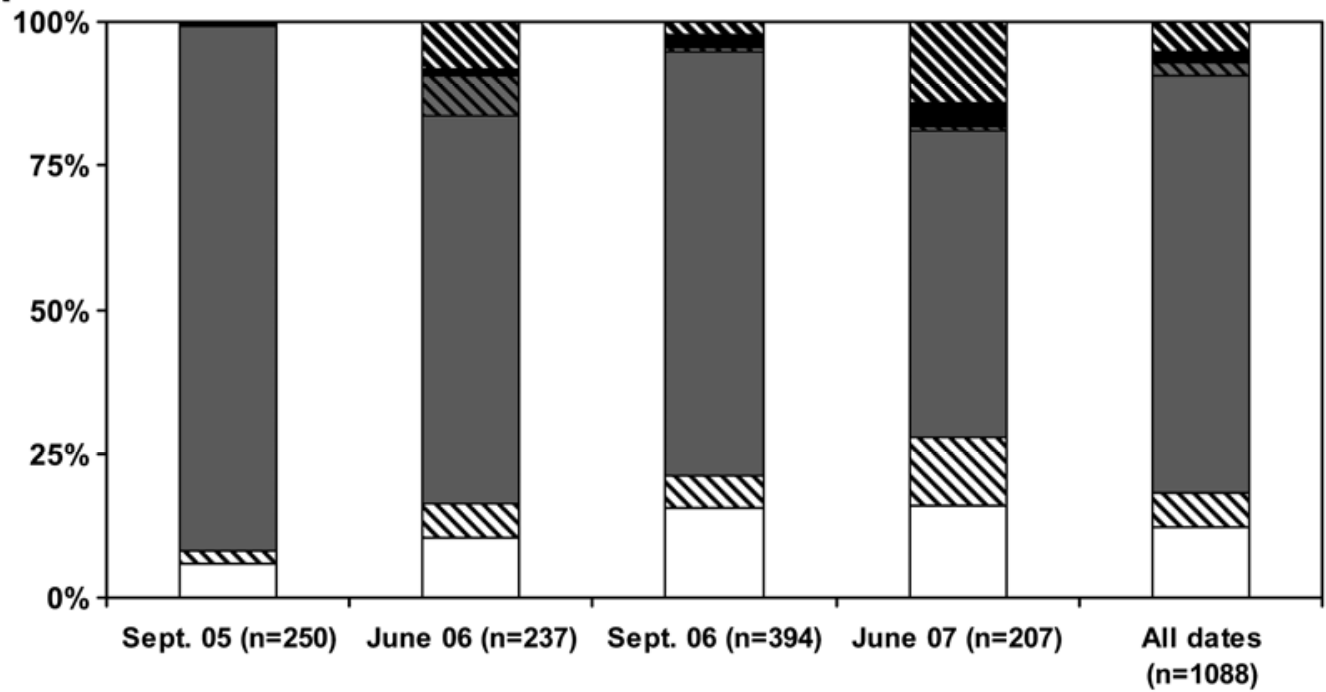

$\square$ cluster Ila $+\mathbf{D}$ cluster Ila $-\square$ cluster IIb $+\Delta$ cluster Ilb - - cluster I $+\mathbf{D}$ cluster I

B

$\mathbf{G} / \mathbf{N}$

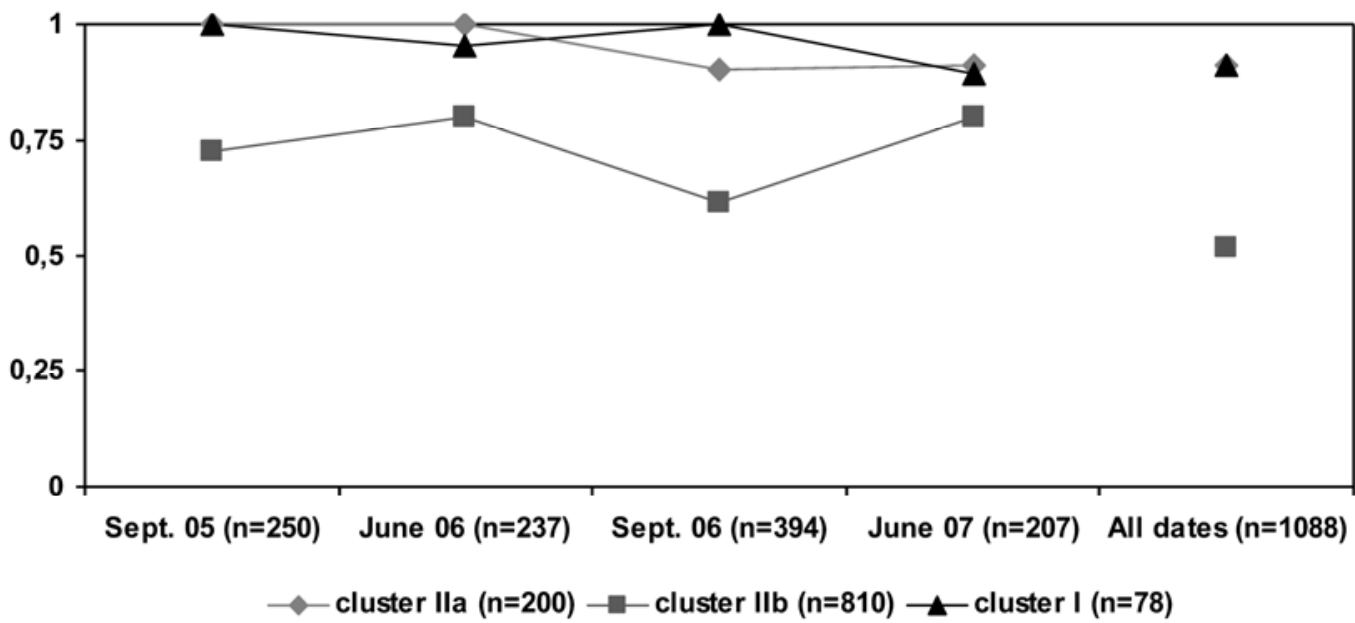

Fig. 4. Changes in the genetic structure of Botrytis over time. A, Frequencies, for each sampling date, of each cluster detected in Structure analysis. For each cluster, we indicate (hatches) the frequency of individuals for which the flipper transposable element was detected (+) or not detected (-). Cluster IIa and cluster IIb are Botrytis cinerea (group II) strains, whereas cluster I contains only B. pseudocinerea (group I) strains. B, Proportion of unique genotypes in each cluster at each sampling date. C, Genotypic diversity in each cluster at each sampling date. D, Multilocus linkage disequilibrium in each cluster at each sampling date. Values marked with an asterisk (*) are significant at the $5 \%$ level. 
eters and conditions should be tested. However, the possibility of allopatric speciation followed by secondary contact cannot be ruled out. Phylogeographic approaches should help to determine which of these two scenarios is the correct one. Surprisingly, $B$. pseudocinerea has rarely been reported outside France. This may be due to poor monitoring in the spring or in other areas and to the lack of discriminatory tools, a problem that this work has rectified (see below). The observation of $B$. pseudocinerea in a limited number of European regions suggests that it may be a "relict species", the survival of which depends on undetermined local adaptation conditions.

Impact of $B$. pseudocinerea in populations and consequences. Our data suggest that $B$. pseudocinerea is present at low frequencies in populations collected from grapevine in France $(0$ to $15 \%$; monitoring data; not shown). Therefore, it is unlikely to have a major effect on gray mold epidemics or to make a substantial contribution to the damage observed on grape berries at harvesting. The management of gray mold may be simpler if we need to consider only one species. The rarity of this species is all the more surprising because $B$. pseudocinerea is naturally resistant (phenotype HydR1) to the hydroxyanilide fungicide fenhexamid $(28,29)$. Because this sterol biosynthesis inhibitor is widely used and because it is highly effective against Botrytis on grapevine and, particularly, as the first treatment (flowering time) of the spraying program, we would expect this species to be selected in populations, which does not seem to be the case according to population survey data. This is consistent with $B$. pseudocinerea being less fit on ripe grapevine berries than $B$. cinerea and with significant differences in the ecological niches of the two species. More generally, fungicide resistance spectrum is one of the only phenotypic criteria of any use for distinguishing between the two species. In routine monitoring, $B$. pseudocinerea strains can be easily recognized, due to their resistance to fenhexamid, particularly in the mycelial growth test, and their hypersusceptibility to fenpropidin, fenpropimorph, and, to a lesser extent, sterol demethylation inhibitors. Analysis of the full spectrum of resistance or susceptibility in an appropriate test is required for clear differentiation of HydR1 strains from those of B. cinerea with acquired resistance to fenhexamid (HydR2, $\mathrm{HydR}^{+}$, and HydR3- ${ }^{-}$phenotypes) $(13,28)$.

In addition to this phenotypic test, many molecular markers are now available for discriminating between the two species. Diagnostic sequence polymorphisms exist in several nuclear genes, such as the vegetative incompatibility locus $B c-h c h$, the sterol $14-\alpha$ demethylase gene cyp 51 , the $\beta$-tubulin gene, the noncoding region $63 \mathrm{R}$, the 3 ketoreductase gene $(3,4,17)$, and the three genes used in our study (G3PDH, HSP60, and MS547). Therefore, PCR-RFLP tests, like that for $B c$ - $h c h$ (17), could be developed. The population genetics analysis conducted in this study also confirmed a unique allele at the microsatellite locus Bc6 (16) for $B$. pseudocinerea. Conversely, the vacuma/transposa genotyping method, based on the presence or the absence of the transposable elements boty and flipper, is clearly irrelevant for distinguishing between the two species. Indeed, although our study showed that
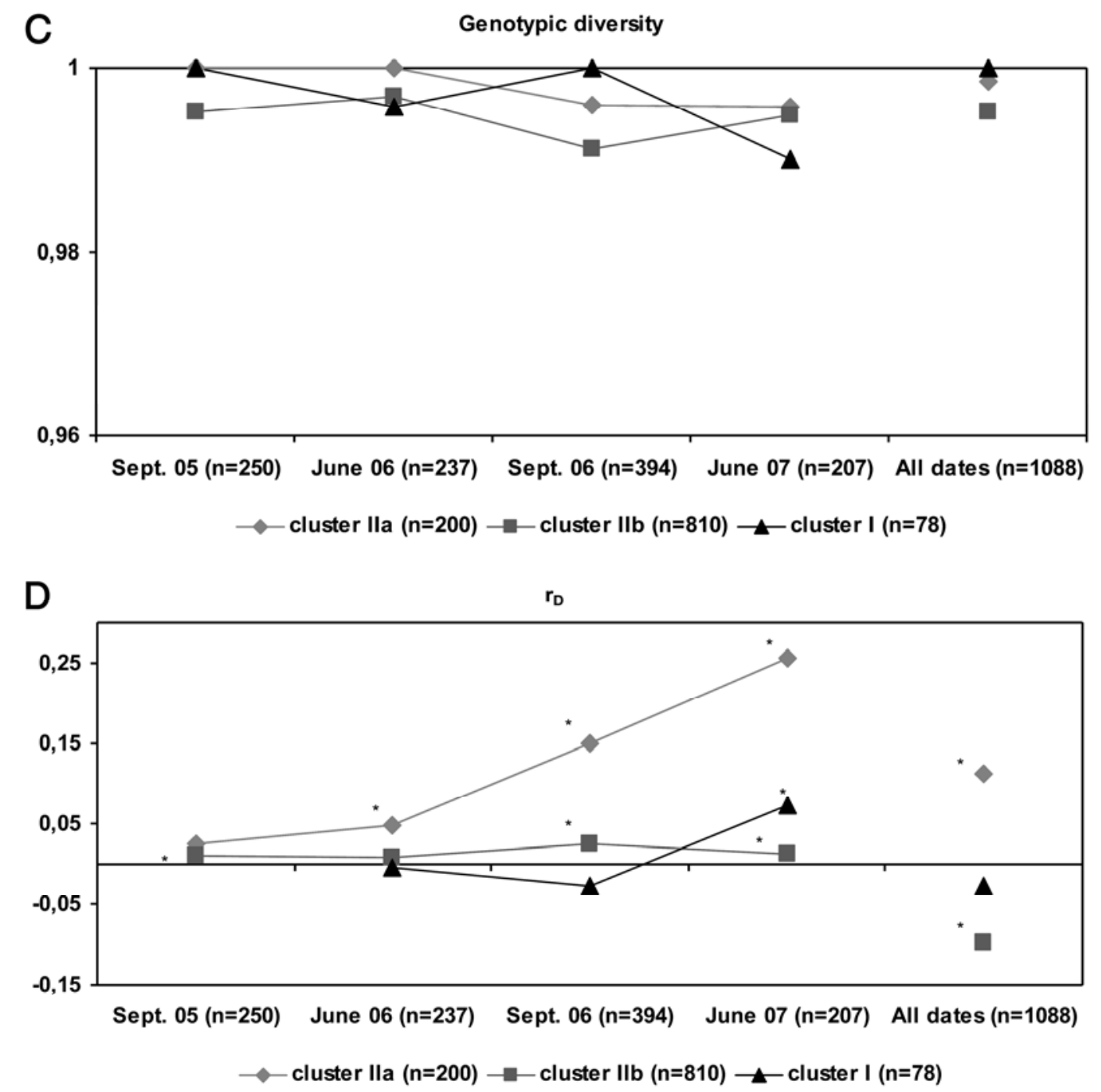

Fig. 4. (Continued from previous page) 


\section{LITERATURE CITED}

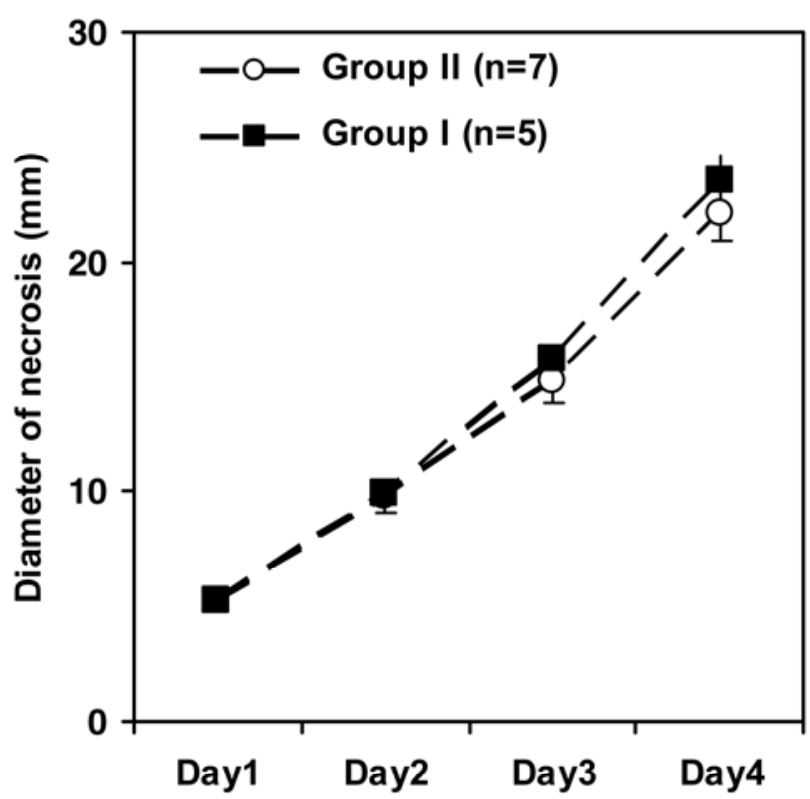

B

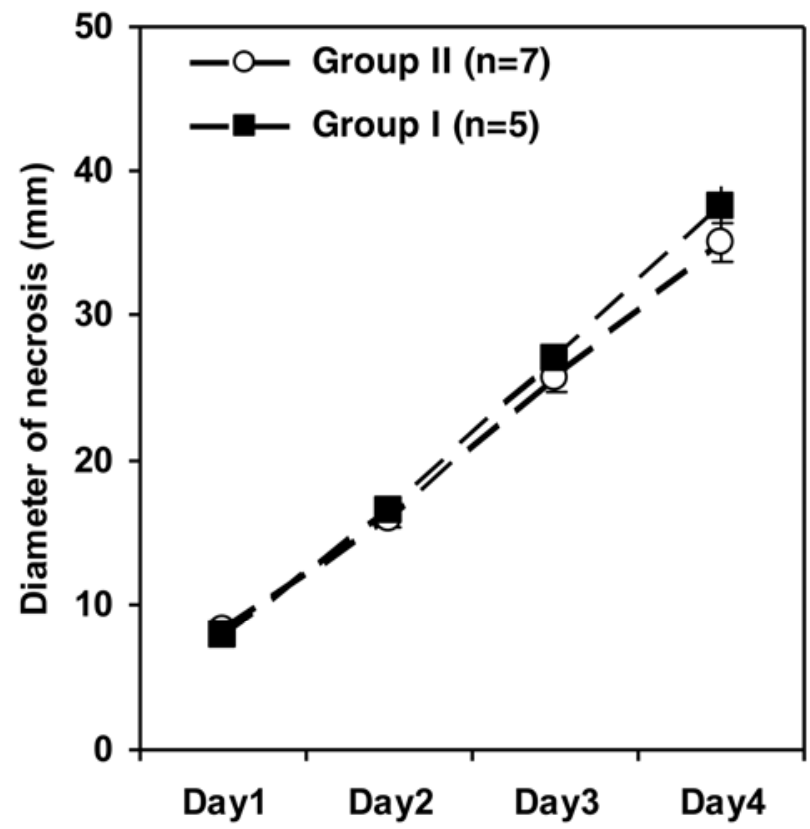

Fig. 5. Comparative aggressiveness of Botrytis cinerea and B. pseudocinerea on $\mathbf{A}$, tomato and $\mathbf{B}$, green bean leaves.

most of the B. cinerea strains harbored the flipper element whereas most of the B. pseudocinerea strains did not, many exceptions were recorded (Fig. 4A) and, therefore, this marker cannot be used for reliable species diagnosis.

\section{ACKNOWLEDGMENTS}

We thank J. van Kan, from the University of Wageningen, Netherlands, for providing the strains of the various Botrytis spp.; M.-L. Panon from the Comité Interprofessionnel des Vins de Champagne, France, for facilitating the collection of Botrytis populations in vineyards; P. Leroux and J.-M. Pradier (INRA) for assistance in the revision of this manuscript; and G. Consiglio (University of Bologna) for help with the Latine diagnosis.
1. Agapow, P. M., and Burt, A. 2001. Indices of multilocus linkage disequilibrium. Mol. Ecol. Notes 1:101-102.

2. Aguileta, G., Marthey, S., Chiapello, H., Lebrun, M. H., Rodolphe, F., Fournier, E., Gendrault-Jacquemard, A., and Giraud, T.kk 2008. Assessing the performance of single-copy genes for recovering robust phylogenies. Syst. Biol. 57(4):613-627. Online publication. doi:10.1080/ 10635150802306527

3. Albertini, C., and Leroux, P. 2004. A Botrytis cinerea putative 3-keto reductase gene (ERG27) that is homologous to the mammalian 17 betahydroxysteroid dehydrogenase type 7 gene (17 beta-HSD7). Eur. J. Plant Pathol. 110:723-733.

4. Albertini, C., Thebaud, G., Fournier, E., and Leroux, P. 2002. Eburicol 14 alpha -demethylase gene (CYP51) polymorphism and speciation in Botrytis cinerea. Mycol. Res. 106:1171-1178.

5. De Queiroz, K. 1998. The general lineage concept of species, species criteria, and the process of speciation: A conceptual unification and terminological recommendations. Pages 57-75. in: Endless Forms: Species and Speciation D. J. Howard and S. H. Berlocher, eds. Oxford University Press, New York.

6. De Queiroz, K. 2007. Species concepts and species delimitation. Syst. Biol. 56:879-886. Online publication. doi:10.1080/1063150701701083

7. Dettman, J. R., Jacobson, D. J., and Taylor, J. W. 2003. A multilocus genealogical approach to phylogenetic species recognition in the model eukaryote Neurospora. Evolution 57:2703-2720.

8. de Vienne, D. M., Giraud, T., and Martin, O. C. 2007. A congruence index for testing topological similarity between trees. Bioinformatics 23:31193124. Online publication. doi:10.1093/bioinformatics/btm500.

9. Diolez, A., Marches, F., Fortini, D., and Brygoo, Y. 1995. Boty, a longterminal-repeat retroelement in the phytopathogenic fungus Botrytis cinerea. Appl. Environ. Microbiol. 61:103-108.

10. Falush, D., Stephens, M., and Pritchard, J. K. 2003. Inference of population structure using multilocus genotype data: linked loci and correlated allele frequencies. Genetics 164:1567-1587.

11. Faretra, F., Antonacci, E., and Pollastro, S. 1988. Sexual behaviour and mating system of Botryotinia fuckeliana, teleomorph of Botrytis cinerea. J. Gen. Microbiol. 134:2543-2550.

12. Felsenstein, J. 1989. Mathematical evolutionary-Theory-Feldman, MW. Science 246:941-942.

13. Fillinger, S., Leroux, P., Auclair, C., Barreau, C., Al Hajj, C., and Debieu, D. 2008. Genetic analysis of fenhexamid-resistant field isolates of the phytopathogenic fungus Botrytis cinerea. Antimicrob. Agents Chemother. 52:3933-3940. Online publication. doi:10.1128/aac.00615-08.

14. Fournier, E., and Giraud, T. 2008. Sympatric genetic differentiation of a generalist pathogenic fungus, Botrytis cinerea, on two different host plants, grapevine and bramble. J. Evol. Biol. 21:122-132. Online publication. doi:10.1111/j.1420-9101.2007.01462.x.

15. Fournier, E., Giraud, T., Albertini, C., and Brygoo, Y. 2005. Partition of the Botrytis cinerea complex in France using multiple gene genealogies. Mycologia 97:1251-1267.

16. Fournier, E., Giraud, T., Loiseau, A., Vautrin, D., Estoup, A., Solignac, M., Cornuet, J. M., and Brygoo, Y. 2002. Characterization of nine polymorphic microsatellite loci in the fungus Botrytis cinerea (Ascomycota). Mol. Ecol. Notes 2:253-255

17. Fournier, E., Levis, C., Fortini, D., Leroux, P., Giraud, T., and Brygoo, Y. 2003. Characterization of Bc-hch, the Botrytis cinerea homolog of the Neurospora crassa het-c vegetative incompatibility locus, and its use as a population marker. Mycologia 95:251-261.

18. Giraud, T., Fortini, D., Levis, C., Lamarque, C., Leroux, P., LoBuglio, K., and Brygoo, Y. 1999. Two sibling species of the Botrytis cinerea complex, transposa and vacuma, are found in sympatry on numerous host plants. Phytopathology 89:967-973.

19. Giraud, T., Fortini, D., Levis, C., Leroux, P., and Brygoo, Y. 1997. RFLP markers show genetic recombination in Botryotinia fuckeliana (Botrytis cinerea) and transposable elements reveal two sympatric species. Mol. Biol. Evol. 14:1177-1185.

20. Giraud, T., Gladieux, P., and Gavrilets, S. 2010. Linking the emergence of fungal plant diseases with ecological speciation. Trends Ecol. Evol. 25:387-395.

21. Giraud, T., Refregier, G., Le Gac, M., de Vienne, D. M., and Hood, M. E. 2008. Speciation in fungi. Fungal. Genet. Biol. 45(6):791-802. Online publication. doi:10.1016/j.fgb.2008.02.001.

22. Giraud, T., Villareal, L., Austerlitz, F., Le Gac, M., and Lavigne, C. 2006. Importance of the life cycle in sympatric host race formation and speciation of pathogens. Phytopathology 96:280-287. Online publication. doi:10.1094/phyto-96-0280.

23. Guindon, S., and Gascuel, O. 2003. A simple, fast, and accurate algorithm to estimate large phylogenies by maximum likelihood. Syst. Biol. 52:696704. Online publication. doi:10.1080/10635150390235520 
24. Isenegger, D. A., Ades, P. K., Ford, R., and Taylor, P. W. J. 2008. Status of the Botrytis cinerea species complex and microsatellite analysis of transposon types in South Asia and Australia. Fungal Divers. 29:17-26.

25. Kasuga, T., White, T. J., and Taylor, J. W. 2002. Estimation of nucleotide substitution rates in eurotiomycete fungi. Mol. Biol. Evol. 19:23182324.

26. Le Gac, M., and Giraud, T. 2008. Existence of a pattern of reproductive character displacement in Homobasidiomycota but not in Ascomycota. J. Evol. Biol. 21:761-772. Online publication. doi:10.1111/j.14209101.2008.01511.x.

27. Le Gac, M., Hood, M. E., Fournier, E., and Giraud, T. 2007. Phylogenetic evidence of host-specific cryptic species in the anther smut fungus. Evolution 61:15-26. Online publication. doi:10.1111/j.1558-5646.2007. 00002.x.

28. Leroux, P., Chapeland, F., Desbrosses, D., and Gredt, M. 1999. Patterns of cross-resistance to fungicides in Botryotinia fuckeliana (Botrytis cinerea) isolates from French vineyards. Crop Prot. 18:687-697.

29. Leroux, P., Fritz, R., Debieu, D., Albertini, C., Lanen, C., Bach, J., Gredt, M., and Chapeland, F. 2002. Mechanisms of resistance to fungicides in field strains of Botrytis cinerea. Pest Manage. Sci. 58:876-888.

30. Leroux, P., Gredt, M., Leroch, M., and Walker, A. S. 2010. Exploring mechanisms of resistance to respiratory Inhibitors in field strains of Botrytis cinerea, the causal agent of gray mold. Appl. Environ. Microbiol. 76:6615-6630. Online publication. doi:10.1128/aem.00931-10.

31. Levis, C., Fortini, D., and Brygoo, Y. 1997. Flipper, a mobile Fot1-like transposable element in Botrytis cinerea. Mol. Gen. Genet. 254:674-680.

32. Ma, Z. H., and Michailides, T. J. 2005. Genetic structure of Botrytis cinerea populations from different host plants in California. Plant Dis. 89:1083-1089. Online publication. doi:10.1094/pd-89-1083.

33. Marthey, S., Aguileta, G., Rodolphe, F., Gendrault, A., Giraud, T., Fournier, E., Lopez-Villavicencio, M., Gautier, A., Lebrun, M. H., and Chiapello, H. 2008. FUNYBASE: a FUNgal phYlogenomic dataBASE. BMC Bioinf. 9. Online publication. doi:45610.1186/1471-2105-9-456.

34. Martinez, F., Blancard, D., Lecomte, P., Levis, C., Dubos, B., and Fermaud, M. 2003. Phenotypic differences between vacuma and transposa subpopulations of Botrytis cinerea. Eur. J. Plant Pathol. 109:479-488.

35. Mayden, R. L. 1997. A hierarchy of species concepts: The denouement in the saga of the species problem. Pages 381-424. in: Species: The Units of Biodiversity. M. F. Claridge, H. A. Dawah, and M. R. Wilson, eds. Chapman and Hall, London.

36. Mayden, R. L. 1999. Consilience and a hierarchy of species concepts: Advances toward closure on the species puzzle. J. Nematol. 31:95-116.

37. Mayr, E. 1940. Speciation phenomena in birds. Am. Nat. 74:249-278.
38. Milicevic, T., Topolovec-Pintaric, S., Cvjetkovic, B., Ivic, D., and Duralija, B. 2006. Sympatric subpopulations of Botrytis cinerea on strawberries based on the content of transposable elements and their connection with resistance to botryticides. Pages 115-118 in: Proc. Vth Int. Strawberry Symp. G. Waite, ed. International Society of Horticultural Sciences, Belgium.

39. Munoz, G., Hinrichsen, P., Brygoo, Y., and Giraud, T. 2002. Genetic characterisation of Botrytis cinerea populations in Chile. Mycol. Res. 106:594-601. Online publication. doi:10.1017/s0953756202005981.

40. Munsell, H. 1975. Munsell Book of Color. Munsell Color Co., Inc., Baltimore, MD.

41. Posada, D., and Buckley, T. R. 2004. Model selection and model averaging in phylogenetics: advantages of akaike information criterion and Bayesian approaches over likelihood ratio tests. Syst. Biol. 53:793808. Online publication. doi:10.1080/10635150490522304

42. Posada, D., and Crandall, K. A. 1998. MODELTEST: Testing the model of DNA substitution. Bioinformatics 14:817-818.

43. Pritchard, J. K., Stephens, M., and Donnelly, P. 2000. Inference of population structure using multilocus genotype data. Genetics 155:945-959.

44. Samadi, S., and Barberousse, A. 2006. The tree, the network, and the species. Biol. J. Linn. Soc. 89:509-521.

45. Staats, M., van Baarlen, P., and van Kan, J. A. L. 2005. Molecular phylogeny of the plant pathogenic genus Botrytis and the evolution of host specificity. Mol. Biol. Evol. 22:333-346. Online publication. doi:10.1093/molbev/msi020.

46. Tajima, F. 1993. Statistical analysis of DNA polymorphism. Jpn. J. Genet. 68:567-595.

47. Tamura, K., Dudley, J., Nei, M., and Kumar, S. 2007. MEGA4: Molecular Evolutionary Genetics Analysis (MEGA) software version 4.0. Mol. Biol. Evol. 24:1596-1599.

48. Tanovic, B., Delibasic, G., Milivojevic, J., and Nikolic, M. 2009. Characterization of Botrytis cinerea isolates from small fruits and grapevine in Serbia. Arch. Biol. Sci. 61:419-429. Online publication. doi:10.2298/abs0903419t.

49. Taylor, J. W., Jacobson, D. J., Kroken, S., Kasuga, T., Geiser, D. M., Hibbett, D. S., and Fisher, M. C. 2000. Phylogenetic species recognition and species concepts in fungi. Fungal. Genet. Biol. 31:21-32. Online publication. doi:10.1006/fgbi.2000.1228.

50. Valiere, N. 2002. GIMLET: a computer program for analysing genetic individual identification data. Mol. Ecol. Notes 2:377-379. Online publication. doi:10.1046/j.1471-8286.2002.00228.x.

51. Yang, Z. H. 2007. PAML 4: Phylogenetic analysis by maximum likelihood. Mol. Biol. Evol. 24:1586-1591. Online publication. doi:10.1093/ molbev/msm088. 